\title{
LA PRIORIDAD EN LA TRAMITACIÓN PARLAMENTARIA DE LOS PROYECTOS DE LEY
}

\author{
PIEDAD GARCÍA-ESCUDERO MÁRQUEZ \\ Letrado de Cortes
}

\section{La primacía de la iniciativa del Gobierno en la Constitución}

La regulación constitucional de la iniciativa legislativa configura a ésta como plural, pero con un pluralismo que ha sido calificado de desigual ${ }^{1} \mathrm{o}$ atenuado ${ }^{2}$, ya que sólo dos de los sujetos citados en el artículo 87 de la Constitución, en concreto los comprendidos en su apartado 1 (Gobierno y Cámaras), son auténticos titulares de la iniciativa legislativa.

El carácter ordinario y prioritario de la iniciativa del Ejecutivo le sitúa en una situación de preeminencia que tiene sus raíces en la propia Constitución. Esta preeminencia debe ser enmarcada en la perspectiva del sistema parlamentario racionalizado que instaura nuestro texto constitucional. En efecto, en los sistemas de rígida separación de poderes no se da la colaboración Gobierno-Parlamento que provoca el esquema iniciativa gubernamental-elaboración parlamentaria de la ley ${ }^{3}$. Será a través de las convenciones constitucionales (mensajes) como irá

1. E. AJA, "Caracteres y principios generales del procedimiento legislativo", Anuari de Dret Politic, 1983, pág. 161.

2. M. GFrpe Lendín, "Relaciones entre las Cortes Generales y las Asambleas de las Comunidades Autónomas. La iniciativa legislativa de las Comunidades Autónomas en la Constitución Española de 1978", Parlamento y Sociedad Civil, Universidad de Barcelona, Barcelona, 1980, pág. 166.

3. A estos dos criterios monista y dualista de atribución de la iniciativa legislativa, se añade la concepción pluralista que responde a la potenciación de la democracia participativa o a estructuras descentralizadas del poder político. 
obteniendo el Presidente de los Estados Unidos un papel en el impulso de la legislación.

Por el contrario, el parlamentarismo racionalizado se basará "en una fuerte integración del Gobierno respecto de la mayoría parlamentaria que le sirve de apoyo" ${ }^{4}$. Surge así la idea de un parlamentarismo cooperativo o de colaboración entre los dos poderes, desde el momento en que, aunque se atribuya al Gobierno la función de dirección política, "para su ejercicio necesita en buena medida de la colaboración parlamentaria"s. Aunque la política general del Gobierno se concreta, y no puede no concretarse en iniciativas e intervenciones administrativas y ejecutivas, deberán encontrar su fundamento previo en actos legislativos, tanto más cuando la intervención debida del Estado sobre sectores cubiertos por la reserva de ley hace indispensable la utilización de instrumentos legislativos. En - este sentido, la iniciativa del Gobierno no es sólo un poder, sino también un deber, con una correlativa responsabilidad, al menos política, de poner en marcha el programa presentado a la Cámara y para el que se le concedió la confianza ${ }^{6}$.

Puede definirse con Sáiz Arnáiz la dirección política como la actividad consistente en el establecimiento de los fines fundamentales de la acción estatal, que compete a los órganos políticos y que implica, en última instancia, la traducción al plano jurídico de las operaciones políticas de las fuerzas de la mayoría de Gobierno $^{7}$. En efecto, la iniciativa es un acto típico de indirizzo político: si gobernar significa elegir fines, el acto de iniciativa, esencialmente acto de selección, sería uno de los principales factores que determinan la realización del programa político gubernativo .

Hay razones que abonan la atribución de esta función al Gobierno, que se han convertido, de tan manidas, prácticamente en tópicos. Cuando se habla de crisis del Parlamento y de ascenso del Ejecutivo, se presenta a éste como órgano reducido, ágil por tanto para adoptar las decisiones que reclama el complejo mundo moderno. La homogeneidad política, el funcionamiento reservado y la continuidad en el ejercicio de sus funciones jugarian también a su favor frente a un Parlamento caracterizado por lo contrario?. Como dice Aja, el Gobierno posee los medios para convertirse en motor de las decisiones políticas fundamentales, y en los regímenes parlamentarios se espera que lo haga ${ }^{10}$.

4. J. L. CASCAjO CASTRO, "La forma parlamentaria de Gobierno en el sistema constitucional español’, en Revista Vasca de Administraciones Públicas, n. ${ }^{\circ} 34,1992$, pág. 13.

5. I. DE OTTO, "La posición constitucional del Gobierno", Organización y funciones del Gobierno, Documentación Administrativa, n. ${ }^{\circ} 188$, Madrid, 1980, pág. 178.

6. F. Cuocolo, Saggio sull'iniziativa legislativa, Giuffrè Editore, Milán, 1971, págs. 42-44.

7. A. SÁIZ ARnÁIZ, "El Gobierno y la dirección de la política", en Revista Vasca de Administración Pública, n. ${ }^{\circ}$ 34, 1992, pág. 189-190.

8. E. SPAGNA Musso, "L'iniziativa nella formazione delle leggi italiane", Il potere di iniziativa legislativa, vol. I, Napoles, 1958, págs. 9-10.

9. P. LuCAS VERDÚ añade como causas favorecedoras de esta tendencia la dilación que provoca el sistema bicameral en el procedimiento formador de la ley, los medios técnicos más eficaces con que cuenta el Gobierno, el influjo de los partidos políticos y las tendencias hacia la personalización del poder. (Iniciativa legislativa", Nueva enciclopedia juridica, tomo XII, Francisco Seix, Barcelona, 1975, pág. 624).

10. E. AJA, "Caracteres y principios generales del procedimiento legislativo", cit., pág. 164. 
Obviamente, pese a este ascenso de los Ejecutivos, el Parlamento, como órgano representante del pueblo, conservará -aunque sea formalmente- el ejercicio de la función legislativa. Pero se producirá una división de competencias en esta materia, que forma parte del entramado interorgánico de relaciones entre Parlamento y Gobierno. Al Gobierno corresponden los actos preparatorios (opciones y decisiones), que suponen al menos una predeterminación "objetual" del trabajo parlamentario $^{11}$, además del ejercicio de la potestad reglamentaria y la función ejecutiva. Pero la relación no es unidireccional, puesto que si el Gobierno impulsa la función de creación normativa de las Cámaras, éstas a través de sus instrumentos de control pueden instarle a que ejercite tanto la iniciativa legislativa ${ }^{12}$, como su potestad reglamentaria.

Los argumentos antes expuestos, aplicables al sistema parlamentario actual, explican, más que el predominio en la iniciativa, el cada vez mayor dominio por el Gobierno en toda la función legislativa, tanto la parlamentaria, como la que le atribuye la Constitución (Decretos-Leyes).

Sin embargo, cuando se circunscriben al ámbito de la iniciativa legislativa, olvidan que, en realidad, ésta ha ido siempre unida a la función ejecutiva: atribuida primero al Rey, en la monarquía constitucional (Carta francesa de 1814, Estatuto Real de 1834), en la monarquía parlamentaria será compartida por el Rey y las Cámaras (Constituciones de 1812, 1837 y posteriores), por considerar que legislar y gobernar sólo son expresiones diferentes de una misma actividad gestora que incumbe al Gobierno, o al binomio Gobierno-mayoría parlamentaria ${ }^{13}$.

Pues, en definitiva, la importancia prevalente de la iniciativa legislativa del Gobierno se funda sobre todo en el papel asumido por el ejecutivo respecto de la actividad parlamentaria, de forma que se reconoce al Gobierno la posición de "comité directivo" de la Cámara ${ }^{14}$, o al menos, de la mayoría que lo sostiene ${ }^{15}$. El Gobierno es el guía de la mayoría. La superación de la dialéctica ParlamentoGobierno vincula al ejecutivo y al legislativo a la orientación política que resulta del programa del Gobierno aprobado por las Cámaras con la concesión de su

11. E. ANGulo Rodríguez, "Comentario al artículo 88: iniciativa legislativa gubernamental", Comentarios a las leyes políticas. Constitución española de 1978, dirigidos por O. Alzaga Villaamil, tomo VII, Edersa, Madrid, 1983-1989, pág. 254. Es lo que RuBßo LlonenTE denomina "la mediatización gubernamental del trabajo de las Cortes", aún más intensa en el ejercicio de la potestad legislativa ("Relaciones del Gobierno y la Administración con las Cortes", Gobierno y Administración en la Constitución, vol. I, Madrid, 1988, pág. 151). En esta misma obra colectiva PÉrez Royo llega a afirmar que "en el Estado democrático, el Gobierno es el titular del poder normativo en general" ("La distribución de la capacidad normativa entre el Parlamento y el Gobierno", pág. 94.)

12. Véase el artículo 174 del Reglamento del Senado, conforme al cual una de la finalidad de las mociones es uque el Gobierno... remita a las Cortes un proyecto de ley regulando una materia de la competencia de aquéllas", contenido, por otra parte, muy frecuente tanto para las mociones como para las proposiciones no de ley presentadas en el Congreso de los Diputados.

13. A. Dorrego de CARLos, "Artículo 88: iniciativa legislativa gubernamental", Comentarios a la Constitución española de 1978, dirigidos por O. Alzaga Villaamil, 2." ed., vol. VII, Edersa, Congreso de los Diputados, Madrid, 1998, pág. 297.

14. Elia, Il governo come "Comittato" direttivo del Parlamento, Civitas, 1951, págs. 59 y ss.

15. Véase sobre el sistema italiano del Gobierno, CRISAFuLL, Aspetti problematici del sistema parlamentere vigente en Italia, Jus, 1958, págs. 167 y ss. 
confianza $^{16}$. En consecuencia, será normalmente el propio Gobierno el que presenta a la Cámara los proyectos de ley de puesta en práctica de su orientación política, y son en consecuencia sobre todo esos proyectos los que obtendrán la aprobación definitiva en el Parlamento. Su tramitación más rápida en el iter procedimental parlamentario y sus mayores posibilidades de convertirse en leyes no se deberán tanto, como se ha sostenido, a su mejor redacción técnica o a su mayor correspondencia con las exigencias del país, cuanto a la relación política que liga al Gobierno con su mayoría parlamentaria, que confiere al Gobierno un papel director de tal mayoría para la realización del programa acordado. Es un dato de hecho que la iniciativa legislativa preeminente es la del Gobierno, y se dice consecuentemente que el Gobierno es el dominus de la actividad legislativa ${ }^{17}$.

Este esquema de predominio gubernamental en la iniciativa legislativa late en el fondo de la regulación contenida en la Constitución de 1978. No porque sea el Gobierno el primer sujeto citado en el artículo 87 , aunque ya hemos visto que tiene sentido la división en apartados y la redacción del apartado 1, en que se enuncian los únicos titulares de la iniciativa legislativa. Tampoco, aunque debe destacarse este dato, porque de los cuatro tipos de iniciativa contenidas en el artículo 87, solamente la gubernamental se encuentra libre de vinculación a normas de remisión, lo que la dota de una vitalidad y espontaneidad de la que carecen los otros tres supuestos ${ }^{18}$.

La primacía del Gobierno en la iniciativa resulta de la combinación de otros preceptos constitucionales:

- Ha de enlazarse, en primer término, con la función de "dirección de la política" que el artículo 97 atribuye al Gobierno. Ésta y las restantes tareas comprendidas en este artículo no serían en la práctica asumibles sin que descansara sobre el Gobierno el peso primordial en el ejercicio del derecho de iniciativa ${ }^{19}$. Iniciativa legislativa y dirección política, como dice Punset, guardan entre sí una relación de medio a fin, por lo que la preeminencia gubernamental en este ámbito se corresponde con la necesidad de instrumentalizar la aplicación del artículo 87, que asigna al Gobierno la dirección de la política ${ }^{20}$. Con estos dos preceptos, 87 y 97, la Constitución sitúa la iniciativa en la línea de la evolución propia del sistema parlamentario racionalizado, antes descrita. La contrapartida será la responsabilidad solidaria ante el Congreso de los Diputados, que el artículo 108 impone al Gobierno.

- No debe olvidarse que el Parlamento ha dado su aprobación al programa de Gobierno que le propuso el candidato a Presidente de Gobierno en la sesión

16. F. Cuocolo, Saggio sulliniziativa legislativa, cit., pág. 15.

17. E. SPagna Musso, "L'iniziativa nella formazione delle leggi italiane", cit., pág. 15.

18. J. F. Mrrino Mrrchán, "Rasgos definidores de la iniciativa legislativa prevista en el artículo 87 de la Constitución", en Revista de Derecbo Político, UNED, n. ${ }^{\circ}$ 17, 1983, pág. 50.

19. M. Herrero LerA, "Comentario al artículo 87: iniciativa legislativa", Comentarios a la Constitución española de 1978, dirigidos por O. Alzaga Villaamil, 2." ed., tomo VII, Edersa, Congreso de los Diputados, Madrid, 1998, pág. 219.

20. R. Punsist, "La iniciativa legislativa en el ordenamiento español", Revista Española de Derecbo Constitucional, n. ${ }^{\circ} 14,1982$, pág. 78. 
de investidura (art. 99.2), otorgando a éste su confianza para la realización de dicho programa, cuyos instrumentos típicos serán las leyes ${ }^{21}$. Ésta es la primera y capital intervención del Parlamento en la dirección política, que tampoco pierde del todo a lo largo de la legislatura, cuando ejerce sus funciones de control y de indirizzo. Como dice Sáiz Arnáiz ${ }^{22}$, se trata de una actividad compartida entre el Gobierno y el Parlamento, si bien a la luz de la primacía del primero. El carácter prioritario de la iniciativa legislativa del Gobierno corresponde a una necesidad concreta del sistema constitucional actual, resultando tal iniciativa de la confianza de las Cámaras, que deben permitirle disponer de los instrumentos legislativos para actuar la dirección política y debe poder impedir la adopción de medidas legislativas contrarias a ella ${ }^{23}$.

- En coherencia con la atribución de una iniciativa ordinaria y predominante al Gobierno, la Constitución sienta los cimientos de esta posición. Básicamente a través de la "aceptación inicial" de los proyectos a que ya hemos aludido, y de la prioridad en su tramitación, que el artículo 89.1 proclama y que los Reglamentos desarrollan en la forma que veremos (inclusión en orden del día, declaración de urgencia, sesiones extraordinarias).

- Aún más, en aquéllas cuestiones que se consideran esenciales para la dirección política, la Constitución reserva la iniciativa al Gobierno. Así ocurre con la Ley de Presupuestos Generales del Estado (art. 134.1), instrumento económico que permite desarrollar una opción política.

- El Gobierno, responsable de la dirección política, puede manifestar su criterio respecto de las iniciativas de las Cámaras e incluso oponerse a su tramitación ${ }^{24}$ si implican aumento de gastos o disminución de ingresos (art. 134.6 CE) ${ }^{25}$. Con estas facultades, se trata de evitar la desviación de la orientación política fijada por el Gobierno. Se mantiene, en el primer caso, la primacía de la voluntad de la Cámara, que se expresará en la toma en consideración, pero el Gobierno debe ser oído.

El riesgo que encierra la generalización del predominio del Gobierno en la iniciativa reside, como señala acertadamente Lucas Verdú, en la desvalorización de los preceptos, constitucionales y ordinarios, que formalmente atribuyen la competencia legislativa a ambos órganos, ejecutivo y legislativo. De otra parte, el aumento de sujetos capacitados para iniciar el procedimiento legislativo sería paralelo al incremento de la iniciativa gubernamental, coadyuvando con el ejecutivo en la tecnificación del poder legislativo: las leyes son impulsadas por equipos técnicos reducidos, y en la práctica la función de las asambleas parlamentarias se constriñe cada vez más al control y la fiscalización. Esto es explicable y plausible

21. De aquí la definición de ley que nos da B. Pendás García («Procedimiento Legislativo y calidad de las leyes", en Revista Española de Derecho Constitucional, n. ${ }^{\circ} 28,1990$, pág. 81), como "acción instrumental de desarrollo del programa política preferido por el cuerpo electoral".

22. A. Sálz ArnáIz, "El Gobierno y la dirección de la política», cit., pág. 195.

23. F. Cuocolo, Saggio sull'iniziativa legislativa, cit., pág. 27.

24. También si son contrarias a una delegación legislativa en vigor (art. $84 \mathrm{CE}$ ).

25. Igualmente para las enmiendas de similares características, presentadas ya en el curso del procedimiento legislativo. 
en el plano estrictamente técnico, pero significa una modificación lenta, pero manifiesta, de los principios de la democracia liberal ${ }^{26}$.

\section{JUSTIFICACIÓN DE LA PRIORIDAD DE LAS INICIATIVAS DEL GOBIERNO}

Conforme al artículo 88 de la Constitución, los proyectos de ley aprobados por el Consejo de Ministros son sometidos al Congreso, acompañados de una exposición de motivos y de los antecedentes necesarios para pronunciarse sobre ellos.

Una vez admitido a trámite un proyecto de ley por la Mesa del Congreso de los Diputados, inicia éste su tramitación parlamentaria. Con el acuerdo de admisión a trámite, la Mesa acuerda asimismo su publicación en el Boletín Oficial de las Cortes Generales, la apertura del plazo de presentación de enmiendas y su envío a la Comisión legislativa competente por razón de la materia, especificando si dicho envío se realiza para dictaminar sobre el proyecto (si versa sobre alguna de las materias excluidas de la delegación en Comisión por el art. 75.3 de la Constitución $)^{27}$ o para que lo apruebe con competencia legislativa plena, por operar la presunción general en este sentido contenida en el artículo $148 \mathrm{RC}$, cuya dudosa constitucionalidad ya hemos tenido ocasión de comentar ${ }^{28}$.

26. P. LuCAS Verisú, "Iniciativa legislativa", cit., pág. 624-626.

27. La reforma constitucional, las cuestiones internacionales, las leyes orgánicas y de bases y los Presupuestos Generales del Estado.

28. Véase P. García-Escunero, "Las especialidades del procedimiento legislativo en el Senado", $V$ Jornadas de Derecho Parlamentario, Congreso de los Diputados, Serie IV, Monografias, n. ${ }^{\circ} 38$, Madrid, 1995, págs. 500-501. Al amparo de la facultad, otorgada a las Cámaras por el artículo 75.2 de la Constitución (E. RfCODER DE CASSO, "Comentario al artículo 75.2", Comentarios a la Constitución, dirigidos por F. Garrido Falla, Madrid, 1985, pág. 1162, considera que este precepto está mal colocado, pues está regulando una variante del procedimiento legislativo en mayor medida que señalando una característica organizativa de las Comisiones), de delegar en las Comisiones legislativas permanentes la aprobación de proyectos o proposiciones de ley, pudiendo el Pleno no obstante recabar en cualquier momento su debate o votación, ambos Reglamentos han introducido entre los procedimientos especiales un procedimiento desconcentrado.

El Reglamento del Senado no establece la aplicación automática del procedimiento descentralizado, a diferencia del Reglamento provisional, según el cual (art. 86.2) «Los (proyectos) que lo bubieran sido por la Comisión competente del Congreso con plenitud de poder legislativo, pasarán a la Comisión correspondiente del Senado, que tendrá el mismo poder, sin exigirse aprobación final en el Pleno del Senado." La regulación establecida en el Congreso de los Diputados tiene la peculiaridad de que, conforme al artículo 148 del Reglamento, el acuerdo del Pleno por el que se delega la competencia legislativa plena en las Comisiones se presume para todos los proyectos y proposiciones delegables (esto es, los no excluidos por el artículo 75.3 de la Constitución: reforma constitucional, cuestiones internacionales, leyes orgánicas y de bases y Presupuestos Generales del Estado) lo que produce la generalización absoluta de este procedimiento que se convierte de hecho en el ordinario. Tan sólo aprueba el Pleno aquellos proyectos respecto de los cuales recabe la deliberación y votación final en la sesión plenaria en que se proceda al debate de totalidad -proyectos- o a la toma en consideración -proposiciones-, trámites que no son delegables, o aquellos otros en que el Pleno acuerde la avocación a propuesta de la Mesa, oída la Junta de Portavoces, antes de iniciarse el debate en Comisión. En consecuencia, E. RfCoder de Casso, "Comentarios al artículo 75.2", cit., pág. 1167, califica la delegación de parcial en el Reglamento del Congreso, porque no se delega el debate de totalidad ni la toma en consideración de las proposiciones de ley, con lo que se garantiza la unidad de orientación política. 
Se inicia así el procedimiento legislativo propiamente dicho, o la fase constitutiva del mismo si adoptamos el criterio de incluir la iniciativa como fase previa. A partir de ahora recorrerá el proyecto fruto de la iniciativa del Gobierno un mismo iter (bien el procedimiento legislativo ordinario, bien alguno de los procedimientos abreviados -lectura única, delegación en Comisión, urgencia-, o específicos en función de la materia-leyes orgánicas, ley de presupuestos) que las proposiciones de ley.

Pero lo cierto es que, además del artículo 88 , regulador de la iniciativa legislativa del Gobierno, la Constitución contiene en el artículo 89, dedicado a las proposiciones de ley, una referencia más a los proyectos, que consagra la prioridad de su tramitación parlamentaria: "La tramitación de las proposiciones de ley se regulará por los Reglamentos de las Cámaras, sin que la prioridad debida a los proyectos de ley impida el ejercicio de la iniciativa legislativa en los términos regulados por el articulo 87.

No dice más la Constitución sobre ula prioridad debida a los proyectos de ley". Son los Reglamentos, pues, los que incluyen disposiciones que la hagan realidad en la tramitación parlamentaria. Este trabajo tiene por objeto identificar los aspectos en que se materializa a lo largo del procedimiento legislativo el principio de prioridad consagrado en la Constitución. En efecto, como señalan De Esteban y López Guerra, la prioridad atribuida por el artículo 89 "parece que deba entenderse no como la atribución metafísica de una cualidad a los proyectos gubernamentales, sino como la exigencia constitucional de que, de alguna manera, se establezca tal prioridad ${ }^{29}$.

Previamente debemos recordar las razones para esta prioridad, que enlazan con la posición preeminente del Gobierno en la iniciativa legislativa.

La prioridad en la tramitación de proyectos de ley debe enmarcarse, como la caracterización de su iniciativa como ordinaria y preferente, en las facultades de dirección política atribuidas al Gobierno, en nuestro caso, por el artículo 97 de la

Este procedimiento ha suscitado en los autores dudas en cuanto a su constitucionalidad. Así, en R. Punset, "La fase central del procedimiento legislativo", en Revista Espáñola de Derecho Constitucional, n. ${ }^{\circ}$ 14, 1985, pág. 130; A. García MarTínez, El procedimiento legislativo, Congreso de los Diputados, serie IV, monografías n. ${ }^{\circ}$ 10, Madrid, 1987, pág. 295; E. Recolder DE. Casso, "Comentario al artículo 75.2", cit., pág. 1168; F. Santaolalla, Derecho Parlamentario español, 1." ed., Espasa-Calpe, Madrid, 1984, pág. 238, y M. SenÉn HernándeZ, "Comentario al artículo 75: el Pleno y las Comisiones", Comentarios a la Constitución española de 1978, dirigidos por O. Alzaga Villaamil, tomo VI, Edersa, Madrid, pág. 550 y ss. Esta autora considera que se produce con esta generalización, que obedece a las necesidades funcionales de las Cámaras modernas, una usurpación de las funciones de la institución plenaria por organismos internos de menor rango de la Cámara, lo que puede encerrar en sí misma una potencial amenaza para la propia institución parlamentaria, lo que es criticado por excesivo por A. Ruz ROBLEDO, "La delegación legislativa en las comisiones parlamentarias", en Revista Española de Derecho Constitucional, n. ${ }^{\circ} 43,1995$, págs 86-87.

La inconstitucionalidad dada se extiende por los autores citados al límite temporal para la avocación por el Pleno establecido por el artículo $149 \mathrm{RC}$ ("antes de iniciarse el debate en Comisión) frente al "en cualquier momento constitucional. El plazo debería extenderse hasta la aprobación final por la Comisión.

29. J. DE Esteban y L. Lópłz Guerra, El régimen constitucional español, Ed. Labor, Madrid, 1992, pág. 139. 
Constitución ${ }^{30}$. En un régimen parlamentario, la cohonestación de este principio con el de soberanía legislativa de las Cámaras se articula mediante una distribución de funciones que genera un sistema de cooperación legislativa. En consecuencia, sin perjuicio de que haya otros titulares de la iniciativa, calificados de secundarios, sin que ello implique una minusvaloración de la importancia de su reconocimiento constitucional, el carácter preferente de la iniciativa legislativa del Gobierno, necesario para que pueda hacer realidad su programa (que a su vez cuenta con la confianza de la Cámara), debe prolongarse a la largo de la tramitación parlamentaria, para asegurar que pueda (evidentemente, si la mayoría parlamentaria así lo quiere y con el contenido que en último término determine $)^{31}$ convertirse en ley, instrumento fundamental de la dirección política.

En efecto, nuestro texto constitucional, que establece un régimen parlamentario racionalizado, "racionaliza" el proceso político y las interacciones Parlamento-Gobierno introduciendo correctivos que alcanzan también al procedimiento legislativo. Con ellos se trata de conjugar el mantenimiento de una posición preeminente de los ejecutivos, incluso en el procedimiento legislativo, con el respeto a la soberanía del Parlamento. En otros regímenes parlamentarios, se fortalece la posición del ejecutivo mediante prerrogativas o privilegios que no solo actúan sobre el procedimiento, intentando acelerarlo o impedir obstrucciones, sino incluso sobre el momento fundamental de adopción de la norma ${ }^{32}$. En el nuestro, la

30. M. Herrero LFRa cree que este reconocimiento constitucional explícito (que sería una consecuencia implícita en la lógica constitucional de los sistemas parlamentarios y en los artículos 87.1,1.3 y 97) no deja de constituir, aparte de una redundancia de más que dudosa virtualidad política, un caso atípico en la historia del constitucionalismo propio y ajeno" "Comentario al art. 87: iniciativa legislativa", cit., pág. 220). En el mismo sentido, J. F. Merino MerChấ, "Rasgos definidores de la iniciativa legislativa prevista en el artículo 87 de la Constitución", cit., pág. 55. Ya en el debate constituyente, el diputado Solé Tura se manifestó en favor de su supresión, por entender "excesivo que se ponga en la Constitución" que los proyectos deben tener prioridad (Diario de Sesiones Congreso de los Diputados n. ${ }^{\circ} 80,2$ de julio de 1978, pág. 2929)

31. Como señala P. PACTET, por mucho que se presente en el momento actual a la ley más como obra del ejecutivo que del legislador (casi todas las leyes proceden de su iniciativa, el Gobierno prepara el texto, sigue su curso en la Comisión parlamentaria, lo incluye en el orden del día, vigila los debates y pide a su mayoría que lo vote, y esta casi segura de que será aprobado, pues en principio posee una mayoría estable y fiable), es decir, que el hecho mayoritario contribuye a reducir la influencia del Parlamento, se adivina sin embargo que, en la realidad, las cosas son menos simples y más matizadas, porque si bien el Gobierno puede hacer frente a los embates de la oposición, no puede arriesgarse a disgustar demasiado a su mayoría. Tiene que convencerla para evitar tener que forzarla demasiado a menudo. (Préface a B. Baufumé, Le droit d'amendement et la Constitution sous la Cinquième République, Librairie générale de droit et de jurisprudence, Paris, 1993, pág.IX).

32. A. Garrorena Morales (El lugar de la ley en la Constitución española, Centro de Estudios Constitucionales, Madrid, 1980, pág. 112-115) cita como ejemplo de este supuesto la legislación vinculada al voto de confianza que contempla el artículo 49 de la Constitución francesa, no solo por permitir sustraer el contenido de un proyecto de ley al debate del Parlamento, obligando a aprobarlo o rechazarlo en bloque si el Gobierno vincula a él su confianza, sino porque condiciona a las Cámaras a no rechazarlo si no se da una crisis de Gobierno. Asimismo constituye un ejemplo, aunque por derroteros técnicos muy distintos, el "estado de emergencia legislativa" previsto por el artículo 81 de la Ley Fundamental de Bonn, que, una vez declarado por el Presidente federal con la aprobación del Bundesrat, permite al Canciller durante seis meses, con el consentimiento de aquel, promulgar los proyectos de ley rechazados por el Bundestag o que éste haya enmendado de modo inaceptable para el Gobierno. 
Constitución alcanza los fines de agilidad pretendidos por mecanismos más conciliables con los presupuestos de un sistema parlamentario, intencionadamente respetuosos con la ley como expresión de la voluntad de un Parlamento representante de la soberanía popular, que no se convierten en concesiones a la posición del ejecutivo, y que actúan sobre el procedimiento desobstruyéndolo, pero no sobre la decisión final, que permanece bajo la soberanía parlamentaria.

Y no sólo eso; el propio artículo 89 se preocupa de fijar un límite general a la posición dominante del Gobierno: que, como dije Aja ${ }^{33}$, no resulte asfixiante para los demás tipos de iniciativas.

\section{MANIFESTACIONES DE LA PRIORIDAD DE LOS PROYECTOS DE LEY}

Hemos señalado que la prioridad debida a los proyectos de ley no es una cualidad metafísica, sino que debe materializarse en aspectos concretos. Con señaladas excepciones ${ }^{34}$, la doctrina no se ha ocupado de forma excesivamente detallada de esta cuestión, que en ocasiones limita a términos puramente temporales de orden de tramitación ${ }^{35}$.

Nosotros pretendemos abordar la cuestión de una forma más completa y general, examinando cuantas manifestaciones de esta prioridad podamos hallar a lo largo de toda la tramitación parlamentaria de los proyectos de ley, en las diferentes fases del procedimiento legislativo, tanto plasmadas en los preceptos reglamentarios como acuñadas por la práctica parlamentaria. Intentaremos seguir para ello el iter procedimental, con un criterio lógico y en la medida de lo posible cronológico.

Los Reglamentos parlamentarios no contienen una regulación sistemática de la tramitación prioritaria de los proyectos de ley. El Reglamento del Senado realiza una declaración general en su artículo 105 ("Los proyectos del Gobierno recibirán tramitación prioritaria sobre las proposiciones de ley"), sin señalar los medios de articulación de tal declaración. El Reglamento del Congreso de los Diputados sólo alude al carácter prioritario, referido a un solo asunto (que puede ser por tanto, de carácter no legislativo), en el apartado 3 del artículo 67, relativo a la fijación del orden del día. Un precepto similar aparece en el artículo 71.1 RS $^{36}$. Obsérvese la diferencia en el verbo empleado, "podrá pedir" la inclusión en el Reglamento del Congreso, podrá incluir en el del Senado, diferencia que en la práctica desaparece, puesto que también en la Cámara Baja se considera que la petición del Gobierno conlleva la inclusión en el orden del día.

Pero, a falta de desarrollo sistemático del principio de prioridad reconocido constitucionalmente, serán los distintos preceptos de los Reglamentos los que hemos de examinar para tratar de entresacar las manifestaciones de aquélla.

33. E. AJA, "Caracteres y principios generales del procedimiento legislativo", cit., pág. 162.

34. R. PUNSET, "La iniciativa legislativa en el ordenamiento español", cit., pág. 75.

35. J. A. SANTAMARía PASTOR, "Comentario al artículo 89", Comentarios a la Constitución, Civitas, Madrid, 1985, pág. 1278-1280; J. F. MERINo MerCháN, "Rasgos definidores de la iniciativa legislativa prevista en el artículo 87 de la Constitución", cit., pág. 55-57. 


\subsection{La presunción de viabilidad de los proyectos de ley}

Cronológicamente, la primera manifestación en el procedimiento legislativo del carácter ordinario y preferente de los proyectos sería lo que Punset ${ }^{37}$ ha denominado la presunción de aceptación preliminar de los proyectos, en el sentido de que se inicia inmediatamente su tramitación parlamentaria, puesto que el acuerdo de admisión de la Mesa del Congreso de los Diputados incluye la orden de su publicación, la apertura del plazo de enmiendas y el envío a la Comisión correspondiente (art. $109 \mathrm{RC}$ ). Por el contrario, las proposiciones de ley precisan del acuerdo de toma en consideración para que se inicie el plazo de enmiendas y se envíen a la Comisión competente (126 RC). Previamente a aquéllas, el Gobierno dispondrá de treinta días para oponerse a la tramitación por implicar aumento de créditos o disminución de ingresos presupuestarios.

Ha de señalarse el paralelismo entre la toma en consideración a que se someten las proposiciones de ley y el debate y votación de totalidad de que son objeto los proyectos de ley. Admitiendo su naturaleza distinta desde el punto de vista conceptual, puesto que en la primera la Cámara, titular de la iniciativa legislativa, hace suya la propuesta procedente de otros sujetos cuya titularidad no es plena, hemos de poner de relieve la identidad de la decisión sobre unas y otros, que en suma implica que el órgano titular del poder legislativo decide -selecciona- aquellos textos sobre los que desarrollará el conjunto de trámites necesarios para convertirlos en leyes.

La diferencia sustancial, más allá del momento procedimental en que la decisión se sitúa (antes o después de abrirse el plazo de enmiendas) y motivadora de esta misma distinción temporal, se encuentra en que los proyectos de ley, producto de la iniciativa ordinaria y prioritaria, gozan de una presunción favorable a su tramitación, que permite iniciar el procedimiento mediante la apertura del plazo citado, aun a sabiendas de que quedará sin efecto si se aprueba una enmienda de totalidad, tanto de devolución como de texto alternativo ${ }^{38}$.

Esta presunción favorable de viabilidad y de "conveniencia pública" de los proyectos (Pérez Serrano) ${ }^{39}$, además de permitir iniciar el procedimiento, traslada

36. Compárense estos preceptos con el artículo 54.3 del Reglamento Provisional del Congreso de los Diputados de 13 de octubre de 1977, según el cual "se reservará la mitad de la semana para los proyectos de ley y comunicaciones del Gobierno, cuando éste les dé carácter prioritario y asi lo solicite.. En cambio, el Reglamento Provisional del Senado de 18 de octubre del mismo año ya incluía en el inciso final del artículo 61.1 un precepto similar al contenido en el actual artículo 71.1 RS, más favorable a la autonomía de la Cámara en la ponderación de las facultades de Parlamento y Gobierno sobre el orden del día.

37. R. Punset, «La iniciativa legislativa en el ordenamiento español», cit., pág. 76.

38. Porque en este último caso deberá publicarse el texto alternativo aprobado y abrirse un nuevo plazo de enmiendas, esta vez exclusivamente sobre el articulado (art. 112.5 RC), pues ya ha habido un pronunciamiento de la Cámara sobre la oportunidad de aquél.

39. Presunción de conveniencia pública que no siempre puede atribuirse a las proposiciones en el sentido de que los proyectos son desarrollo del programa apoyado por la mayoría de los ciudadanos, de ahí la presunción de que sus alternativas legislativas satisfacen deseos generales, frente al valor parcial que se atribuyen a las proposiciones respaldadas por grupos minoritarios (N. PÉrez SErraNO, Tratado de Derecho Político, Civitas, Madrid, 1976, pág. 790). 
a los grupos parlamentarios la carga de instar que se produzca el debate de totalidad, mediante la presentación de enmiendas de este carácter ${ }^{40}$.

En efecto, sólo habrá debate y votación de totalidad si se hubieran presentado enmiendas de tal naturaleza en el plazo reglamentario (art. 112.1 RC ). Concluido el plazo de enmiendas sin que se hayan presentado aquéllas, podrá iniciarse el debate en Comisión mediante la designación de una Ponencia (art. 113.1 $\mathrm{RC}$ ). Por el contrario, las proposiciones de ley, cualquiera que sea su origen, han de ser necesariamente sometidas al debate y votación de toma en consideración. Dado que ello requiere la inclusión en el orden del día de una sesión plenaria, es posible que muchas de ellas no inicien nunca su tramitación parlamentaria.

Las enmiendas a la totalidad son aquellas que versan sobre la oportunidad, los principios o el espíritu del proyecto de ley y postulan su devolución al Gobierno, o aquellas que proponen un texto completo alternativo al proyecto (art. 110.3 $\mathrm{RC}$ ). A diferencia de las enmiendas al articulado (que junto con las preguntas al Gobierno son prácticamente las únicas iniciativas que quedan abiertas al diputado individual, bien que con la firma del portavoz del Grupo a que pertenezca "a los meros efectos de conocimiento", trámite subsanable antes del comienzo de la discusión en Comisión, según el artículo 110.1 RC), sólo pueden ser presentados por los Grupos parlamentarios. ${ }^{41}$

Mucho más frecuentes son las enmiendas a la totalidad de devolución que las de texto alternativo, dada la necesidad de elaborar éste, sin garantías de su aprobación, o, más bien, con escasas esperanzas de éxito. Se presentarán los que no entrañan una redacción compleja, o aquellos de los que ya se dispone, bien por haberse elaborado con anterioridad una proposición de ley sobre la materia, bien porque el actual Grupo en la oposición antes estuvo en el Gobierno y cuenta con el proyecto de ley entonces elaborado.

El Presidente de la Comisión traslada al Presidente del Congreso las enmiendas a la totalidad presentadas, para su inclusión en el orden del día del Pleno. Una vez que se hayan incluido en el orden del día, el debate de totalidad se desarrollará con un turno a favor y otro en contra, de quince minutos cada uno, para cada una de las enmiendas presentadas, seguidos de la fijación de posición por los restantes Grupos parlamentarios en intervenciones que no podrán exceder de diez minutos (arts. 112.2 y $74.2 \mathrm{RC}$ )

Terminado el debate, el Presidente somete a votación las enmiendas a la totalidad defendidas (esto es, las no retiradas o decaídas por no estar presentes sus autores), comenzando por aquellas que propongan la devolución del proyecto al Gobierno. Este es un primer pronunciamiento categórico, de admisión o rechazo

40. En caso de formularse estas enmiendas, dice R. PUnset, los proyectos regresan cle la fase decisoria a la introductoria del procedimiento legislativo, habiéndose iniciado la primera por la presunción de aceptación liminar ("Procedimiento legislativo", cit., pág. 780).

41. Las enmiendas presentadas son calificadas por la Mesa de la Comisión competente, que determina las que lo son a la totalidad y las que supongan aumento de los créditos o disminución de los ingresos presupuestarios, conforme la Resolución de la Presidencia de 12 de enero de 1983. Contra el acuerdo de calificación de la Mesa de la Comisión, el enmendante puede interponer reclamación ante la Mesa de la Cámara. 
del proyecto de ley, que coloca a la Cámara, al menos en teoría, en una posición de supremacía sobre la propia iniciativa preferente y prioritaria del Gobierno. La Cámara es dueña de su orden del día y de su programa de trabajo. La Cámara decide qué proyectos quiere tramitar. La iniciativa del Gobierno, por muy preeminente que sea, no deja de ser una iniciativa, que no puede imponer a las Cámaras.

Las enmiendas de devolución, en caso de ser varias, se votan conjuntamente, pues el objeto del pronunciamiento es idéntico, cualquiera que sea su motivación. Si el Pleno acuerda la devolución del proyecto ${ }^{42}$, éste queda rechazado y el Presidente del Congreso lo comunica al Gobierno.

En caso de ser rechazadas (o de que no se hayan presentado) las enmiendas de devolución, se votarán las de texto alternativo, éstas sí en forma separada, por el orden de su presentación. Si se aprobara alguna de ellas, se dará traslado del texto a la Comisión correspondiente, publicándose en el Boletín Oficial de las Cortes Generales y abriéndose nuevo plazo de enmiendas, que sólo podrán formularse, como hemos indicado, sobre el articulado (art. 112.5).

De rechazarse todas las enmiendas de totalidad, al igual que si no se hubieran presentado enmiendas de este tipo, la Comisión puede iniciar el procedimiento, mediante la designación de una Ponencia que redacte un informe sobre las enmiendas.

Tras el debate de totalidad y una vez que la Cámara se ha pronunciado en favor de la tramitación del proyecto, en la misma sesión plenaria, o antes de iniciarse el debate de Comisión si aquel debate no se produce por ausencia de enmiendas de tal carácter, el Pleno decide si desea avocar la deliberación del proyecto, es decir, si destruye la presunción que el artículo 148 RC establece en favor de la delegación legislativa plena en Comisión para todos los proyectos constitucionalmente delegables. La propuesta de avocación, que se somete a votación sin debate previo, procede, según el Reglamento, de la Mesa, oída la Junta de Portavoces. La práctica parlamentaria muestra que basta con la solicitud dirigida a la Mesa por un Grupo parlamentario y la audiencia de la Junta de Portavoces para que se someta al Pleno la avocación como asunto previo, no incluido en el orden del día formal, no existiendo tampoco oposición en la adopción por asentimiento de un acuerdo en tal sentido.

La práctica es atinada, cualesquiera que sean sus razones. Las nuestras se refieren a la dudosa constitucionalidad, ya apuntada, de la presunción de delegación en las Comisiones: conforme al artículo 79.3 de la Constitución, el voto de senadores y diputados es personal e indelegable. Podría, al menos, requerirse (con

42. Tenemos el ejemplo reciente de aprobación de la devolución al Gobierno del Proyecto de Ley de Presupuestos para 1996, junto con otros proyectos. La retirada de los apoyos nacionalistas a un Gobierno minoritario originó este hecho insólito en nuestro país y forzó, bien que con cierto retraso, la disolución anticipada de las Cámaras y la consiguiente convocatoria de elecciones generales (Sobre la eficacia del rechazo de los presupuestos sobre la dimisión del Gobierno, véanse las opiniones divergentes de F. Ruibio LloRente, "Presupuestos democráticos", publicado en el diario El País, el 16 de octubre de 1995 y J. PÉriz Royo, "La regla del juego", publicado en el diario El País, el 10 de noviembre de 1995). 
posibilidad de obtenerse) la declaración de inconstitucionalidad por el Tribunal Constitucional de una ley tramitada por el procedimiento desconcentrado contra la oposición de un Grupo parlamentario.

Una última observación sobre las enmiendas a la totalidad de devolución. No siempre se motivan éstas suficientemente sobre la base de "la oportunidad, los principios o el espíritu del proyecto de leyn. En realidad, su presentación persigue una finalidad política: bien obtener un debate plenario sobre el proyecto, con la consiguiente repercusión sobre la opinión pública, bien hacer uso de uno de los instrumentos de obstruccionismo que el Reglamento pone a disposición de las minorías, prolongando la tramitación del proyecto, bien ambas a la vez.

La falta de justificación reglamentaria podría ser causa de inadmisión, aunque en la realidad nunca ocurre así. No sólo para evitar esa necesidad de motivación, lo cierto es que la tendencia va hacia la generalización del debate de totalidad, sin necesidad de que lo inste la presentación de enmiendas. En este sentido irían los borradores de reforma del Reglamento del Congreso de los Diputados en preparación en la VI Legislatura, como también la nonata propuesta que llegó a Dictamen de la Comisión del Reglamento en 1993 (art. 120) ${ }^{43}$, con buen criterio, porque, como dice Pendás, sería conveniente establecer la obligatoriedad de una "primera lectura" política en el Pleno para todos los proyectos, con lo que no sólo se eliminarían ficciones en la presentación de enmiendas, sino que, además, se lograría fijar criterios políticos y legislativos que sirvan de marco al debate posterior ${ }^{44}$.

Hasta ahora nos hemos referido al inicio de la tramitación de los proyectos de ley en el Congreso de los Diputados. Recordemos que hay uno, el proyecto de ley del Fondo de Compensación Interterritorial, que inicia su tramitación en el Senado.

Este proyecto es remitido al Senado, y se tramita siguiendo el procedimiento legislativo ordinario, "con excepción de lo previsto en los artículos 106 y concordantes" (art. 140.1 RS). El artículo 106 se refiere al plazo constitucional de dos meses para aprobar expresamente los proyectos, o para, mediante mensaje motivado, oponer un veto o introducir enmiendas.

Está clara la exclusión del plazo, pero plantea dudas la cuestión de si pueden plantearse enmiendas de veto (¿de veto a qué?), y en caso negativo, si caben las enmiendas de devolución al Gobierno, que no están previstas en el Reglamento. Creemos que, ante la laguna reglamentaria, deben instrumentarse éstas bajo el técnicamente incorrecto título de propuestas de veto, y que su debate y votación deben permitir el mismo juicio preliminar de la Cámara Alta sobre el proyecto del

43. Publicado en el BOCG, Congreso de los Diputados, Serie B, n. ${ }^{\circ} 140$, de 7 de abril de 1993 , pág. 215. También en algunos Parlamentos autonómicos, como en el Reglamento del Parlamento de Andalucía, a partir de la reforma de 1991, aunque mantiene las enmiendas a la totalidad (art. 110, 112 en el Reglamento vigente de 1995). Así se evita, dice J. Cano Br moso ("Cuestiones de técnica jurídica en el procedimiento legislativo del Estado social", La técnica legislativa a debate, Asociación Española de Letrados de Parlamentos, Madrid, Tecnos, 1994, pág. 215) "esta suerte de fraude procedimental" de carencia de motivación de las enmiendas de devolución.

44. B. Pfndés García, "Procedimiento Legislativo y calidad de las leyes", cit., pág. 91. 
Fondo de Compensación Interterritorial que desarrolla el Congreso de los Diputados en el debate de totalidad de los restantes proyectos de ley ${ }^{45}$.

\subsection{La inclusión en el orden del día de los proyectos de ley}

La presentación, admisión a trámite y conclusión del plazo de enmiendas de un proyecto de ley no garantiza su pronta tramitación. Para que esta se produzca, es necesario que el proyecto sea informado por la Ponencia, que este informe se incluya en el orden del día de una sesión de la Comisión correspondiente y, a su vez, el dictamen emitido por ésta forme parte del orden del día de una sesión plenaria.

Ello quiere decir que, de alguna forma, la prioridad debida a los proyectos de ley reconocida por el artículo 89 de la Constitución debe tener reflejo en su inclusión en el orden del día.

El precepto constitucional da lugar a una declaración general por el artículo 105 del Reglamento del Senado, según el cual "los proyectos del Gobierno recibirán tramitación prioritaria sobre las proposiciones de ley". El Reglamento del Congreso carece de una declaración similar, pero tampoco puede decirse que la inconcreción de la contenida en el Reglamento del Senado tenga gran utilidad. Por eso nos interesa examinar, de una parte, los preceptos en los que tal prioridad se manifiesta efectivamente, y, de otra parte, si en la práctica la inclusión de asuntos del orden del día respeta la prioridad debida de los proyectos de ley.

Tanto el Reglamento del Congreso como el del Senado (arts. 67.3 RC y 71.1 RS) permiten al Gobierno incluir en el orden del día del Pleno un asunto (un solo asunto, especifica el Reglamento del Senado) con carácter prioritario. Estos preceptos muestran una disparidad en el término utilizado ("podrá pedir que.... se incluya" en el Reglamento del Congreso; "podrá incluir" en el Reglamento del Senado) que no ha provocado disparidades en cuanto a su aplicación: en ambas Cámaras, reunida la Junta de Portavoces para fijar con el Presidente (en el Congreso; para ser oída en la fijación, en el Senado) el orden del día de una sesión determinada, el representante del Gobierno (Secretario de Estado o Director General de Relaciones con las Cortes) solicita la inclusión de un asunto (que puede ser no legislativo), que se incluye forzosamente ${ }^{46}$.

Ello significa que el Gobierno dispone de un punto de cada sesión plenaria, entendida como aquella que tiene unidad de convocatoria y orden del día. Normalmente, cada sesión consta de varios días, integrando una sola sesión los de cada semana. Esta facultad le permite adecuar a su calendario legislativo la tramitación de los proyectos, cuando éstos no cuenten con la mayoría necesaria para

45. En el mismo sentido, R. PunseT, "La fase central del procedimiento legislativo", cit., pág. 127, y también la práctica parlamentaria. Véase, por ejemplo, BOCG, Senado, n. 22 b), de 15 de septiembre de 1983.

46. En el juego normal de la cortesía parlamentaria, el Gobierno puede solicitar la inclusión de distintos asuntos, que se incluirán si ningún Grupo se opone a ello. Pero lo que caracteriza a los preceptos citados es que, aun con esta oposición, pueda incluirse un asunto en cada sesión plenaria a solicitud del Gobierno. 
ser incluidos en el orden del día del Congreso ${ }^{47}$, cuya fijación realiza el Presidente con el acuerdo; para el que basta la mayoría simple, de la Junta de Portavoces (67.1 RC). En el Senado, el Presidente fija el orden del día, de acuerdo con la Mesa, oída la Junta de Portavoces.

En ambas Cámaras recibe un tratamiento específico, como veremos a continuación, el Proyecto de Ley de Presupuestos Generales del Estado, que goza de preferencia en la tramitación sobre los demás trabajos de la Cámara (133.2 RC, 148.1 RS). Ello es consecuencia de las exigencias de plazo impuestas por el artículo 134.4 de la Constitución, y provoca que se prevea siempre una sesión plenaria ad boc para el debate presupuestario, primero en el Congreso en el mes de noviembre, y luego en las dos Cámaras en el mes de diciembre, primero en el Senado y luego en el Congreso para aceptar o rechazar las enmiendas introducidas por aquél.

Además de los preceptos reglamentarios, nos interesa conocer la práctica parlamentaria en torno a la inclusión de asuntos en el orden del día, para ver si respeta la prioridad constitucionalmente reconocida a los proyectos de ley. Téngase en cuenta que ha desaparecido la regla contenida en el artículo 54.3 del Reglamento provisional del Congreso, según el cual: "en todo caso, se reservará la mitad de la semana para los proyectos de ley y comunicaciones del Gobierno, cuando éste les dé carácter prioritario y así lo soliciten, probablemente para obedecer al mandato constitucional de no impedir el ejercicio de otras iniciativas ${ }^{48}$.

En el Congreso de los Diputados, cada sesión plenaria de las tres que se celebran al mes, responde al esquema siguiente ${ }^{49}$ :

- Los martes se dedican a las proposiciones de ley (2), proposiciones no de ley (2) y mociones consecuencia de interpelación (2 ó 3, en función de las interpelaciones debatidas en la anterior sesión plenaria).

- Los miércoles se dedican al control del Gobierno (preguntas e interpelaciones), sin adoptarse acuerdos.

- Los jueves contienen la materia estrictamente legislativa, normalmente por este orden: convalidación de Decretos-Leyes, enmiendas del Senado sobre textos legislativos, dictámenes de Comisiones sobre aquellos o sobre convenios internacionales (Comisión de Asuntos Exteriores), debates de totalidad sobre proyectos de ley y otros asuntos variados: informes de subcomisiones, informe del Defensor del Pueblo, etc.

47. Para la inclusión de un asunto por el Gobierno, éste debe haber cumplido los trámites reglamentarios que le hagan estar en condiciones de ser incluido en el orden del día (art. $67.3 \mathrm{RC}$ ). En otro caso, se requerirá para la inclusión por razones de urgencia la unanimidad de los Grupos (art. 67.4 RC).

48. E. ANGULo RoDrigunz señala que, en las diversas legislaturas postconstitucionales anteriores al Reglamento vigente, habían sido constantes las quejas de los grupos de oposición respecto al bloqueo de sus proposiciones, por aducir el Gobierno el propósito de remitir un proyecto sobre la misma materia ("Comentario al artículo 88: iniciativa legislativa gubernamental”, cit., pág. 251). Este argumento continúa utilizándose, si no para oponerse a la tramitación, al menos para no acelerarla en los cásos en que la subsanación de un trámite reglamentario exige la unanimidad en la Junta de Portavoces.

49. Con las excepciones derivadas de la inclusión de asuntos excepcionales, como la comparecencia del Gobierno (normalmente en la sesión de los miércoles), o el debate en exclusiva del Proyecto de Ley de Presupuestos. 
La sesión será de mañana o tarde en función de la longitud del orden del día, si bien suele acordarse de antemano la duración en la Junta de Portavoces del martes en que se inicia la sesión plenaria ${ }^{50}$.

La prioridad debida a los proyectos de ley se manifiesta en primer lugar en el tratamiento que reciben las proposiciones. Por acuerdos de la Junta de Portavoces adoptados al principio de las últimas legislaturas, se incluyen dos en cada sesión plenaria semanal para su toma en consideración, de las cuales sólo una de la primera sesión del mes se reserva a una iniciativa procedente de las Comunidades Autónomas o de la iniciativa popular. A su vez, la inclusión de éstas alterna propuestas de reforma de Estatutos de Autonomía ${ }^{51}$ con proposiciones de ley, y dentro de éstas se alternan las autonómicas con las populares, dentro de cada subgrupo por el orden cronológico de su presentación.

Esto quiere decir que se debate la toma en consideración de proposiciones de ley de origen autonómico o popular cada cuatro meses, si hay en espera propuestas de reforma de Estatutos, con el consiguiente retraso en su tramitación, si es que son tomadas en consideración. ¿Es esto concorde con la prohibición contenida en el artículo 89 de que se impida el ejercicio de la iniciativa legislativa en los términos regulados por el artículo 87 ? Si no es contrario, al menos es un cumplimiento poco generoso.

El debate de totalidad de los proyectos de ley, por el contrario, se incluye de oficio en el borrador de orden del día que se somete a la Junta de Portavoces, una vez que concluye el plazo de enmiendas. Sólo se excluirá de ese orden del día si así lo solicita algún Grupo o el Gobierno (que puede estar negociando el consenso sobre el proyecto) y lo acuerda la mayoría de la Junta.

Lo mismo ocurre con las restantes fases del procedimiento, aunque en este caso ya no difieren los proyectos de las proposiciones tomadas en consideración. A medida que se van aprobando los dictámenes de Comisiones o las enmiendas del Senado, su inclusión será automática en el orden del día, salvo que alguien solicite su exclusión y así se acuerde.

En el Senado, la inclusión en el orden del día presenta un carácter secundario, puesto que en último término deberá respetarse el plazo de dos meses (de veinte días, en el procedimiento de urgencia) impuesto por el artículo 90.2 de la Constitución (referido, por otra parte, a los proyectos de Ley) y recogido en el artículo $106 \mathrm{RS}$.

Este plazo origina que los textos legislativos (pues también se ha entendido aplicable a las proposiciones, al tramitarse por el procedimiento legislativo ordinario) se incluyen en el orden del día de la sesión plenaria al menos inmediatamente anterior a que concluya dicho plazo, como aclara el artículo $118 \mathrm{RS}$ : $₫ \mathrm{El}$

50. Sin perjuicio de acuerdos, más o menos respetados, adoptados al principio de cada legislatura. En las últimas, por ejemplo, en el sentido de prolongar la sesión por la tarde tan sólo la primera sesión del mes, que se celebra habitualmente en la segunda semana.

51. En ocasiones, ha sido necesario modificar este sistema para dar entrada a varias propuestas de reforma de Estatutos, por la necesidad de que estuvieran éstos modificados en determinada fecha, como, por ejemplo, para la convocatoria de elecciones. 
debate en el Pleno deberá concluir antes de que se cumpla el plazo de dos meses a que se refiere el artículo 106..

La Norma supletoria para la ordenación del debate, de 14 de febrero de $1984^{52}$, señala que corresponde al Presidente de la Cámara tomar las medidas necesarias para que se cumpla en todo caso el plazo constitucional. Para ello, puede fijar el tiempo máximo de debate de un proyecto, distribuyéndolo ente las intervenciones previstas. Una vez agotado dicho tiempo, se procederá a realizar las votaciones que quedasen pendientes.

Hasta aquí nos hemos referido al orden del día del Pleno de la Cámara. Pero no debemos olvidarnos del orden del día de las Comisiones, porque de ellas depende que un proyecto (lo mismo vale para las proposiciones tomadas en consideración) llegue a convertirse en ley o se quede a dormir el sueño de los justos hasta el fin de la legislatura: lo que se llama un proyecto aparcado.

A través de la fijación del orden del día en las Comisiones puede determinarse la concordancia necesaria entre las exigencias de la realización de los fines de política legislativa correspondientes a la dirección política del Gobierno y la actividad legislativa del Parlamento, de conformidad con la posición necesariamente preeminente del Gobierno en la dirección de la actividad de la mayoría parlamentaria. Como dice Manzella ${ }^{\lceil 3}$, los poderes de fijación del orden del día en la Asamblea y en las Comisiones no pueden prescindir de estos puntos firmes: realización del programa legislativo y efectividad del control.

El orden del día de las Comisiones en el Congreso de los Diputados se fija por su Mesa, de acuerdo con el Presidente de la Cámara, teniendo en cuenta el calendario fijado por la Mesa del Congreso (art. 67.2 RC). Una Instrucción sobre funcionamiento de las Comisiones, adoptada por la Mesa de la Cámara el 10 de febrero de 1987, estimula la tramitación de las solicitudes de comparecencia, proposiciones no de ley y preguntas orales pendientes, es decir, de los instrumentos de control, pero para nada alude a los textos legislativos.

De otra parte, frente al procedimiento legislativo en el Senado, que está absolutamente dominado por el elemento tiempo, impuesto imperativamente por el artículo 90.2 de la Constitución ${ }^{54}$, el procedimiento legislativo común regulado por el Reglamento del Congreso de los Diputados apenas si fija un plazo de quince días para presentar enmiendas (sin aludir a su posible ampliación, aunque al amparo del artículo $91 \mathrm{RC}$ la Mesa la autoriza, en ocasiones varias veces) y quince días ampliables para la elaboración del informe de la Ponencia; no se fijan plazos para otras fases de este procedimiento, salvo el de cuarenta y ocho horas desde la terminación del dictamen (el doble que en el Senado) para la presentación de votos particulares. Si bien el artículo $43.2 \mathrm{RC}$ establece un plazo general

52. BOCG Senado, Serie I, n. ${ }^{\circ} 66$, de 28 de febrero de 1984.

53. A. Manzella, "Note sull’ organizzazione dei lavori parlamentari", en Tempi moderni, n. ${ }^{\circ} 2$, 1967-68, pág. 8.

54. El plazo de dos meses de que se dispone para vetar o enmendar el texto se convierten en veinte días naturales en el caso de ser declarado urgente el proyecto por el Gobierno o el Congreso de los Diputados, plazo calificado de simbólico por J. A. SANTAMAría PAstor, "Comentario al artículo 89", cit.; pág. 1284. 
de dos meses para la tramitación de cualquier asunto por una Comisión -aunque el mismo precepto admite la posibilidad de su ampliación-, lo cierto es que la tramitación de un proyecto o proposición en el Congreso de los Diputados no tiene una duración fija -o media, por decirlo así-, dependiendo de la voluntad política la celeridad o lentitud de la tramitación o que un proyecto se estanque en una fase determinada. De ahí que las consecuencias de la declaración de urgencia sean muy relativas en el Congreso de los Diputados, puesto que su efecto consiste en que la duración de los plazos establecidos con carácter ordinario (que como hemos visto son pocos) se reducen a su mitad.

Recordemos a título de ejemplo que de los tres meses que el artículo 134 de la Constitución fija como mínimo para la aprobación de los Presupuestos Generales del Estado, corresponden ordinariamente dos a la tramitación en el Congreso y uno (normalmente no completo) al Senado. Quizá esta sea la tónica general de los restantes proyectos: relación de 2 a 1, cuatro meses de tramitación en el Congreso de los Diputados y dos en el Senado.

En definitiva, será pues la voluntad política de la mayoría (que coincide normalmente con la del Gobierno) la que decida la inclusión de un proyecto en el calendario de trabajos de la Comisión con mayor o menor premura, o simplemente su estancamiento. Esto permite presentar proyectos de ley o tomar en consideración proposiciones (en particular procedentes de Grupos minoritarios que apoyan al Gobierno) como gesto político, sin ninguna intención de que lleguen a convertirse en leyes ${ }^{55}$.

A la inversa, si el Gobierno quiere activar la tramitación de un proyecto de ley en Comisión, no puede ya recurrir (como en el Pleno, al que se entienden referidos los artículos 67.3 RC y 71.1 RS) a la inclusión de un asunto con carácter prioritario, sino que acudirá a la mayoría de que disponga en la Mesa de la Comisión. Por eso es importante disponer de un Presidente de Comisión afín, y cuando se desea ceder a la oposición Presidencias simbólicas, corresponderán, como ha ocurrido en las últimas legislaturas, a Comisiones más relacionadas con el control del Gobierno (Presupuestos, Control de RTVE) o de importancia legislativa secundaria (Educación y Cultura, si no hay en marcha grandes proyectos de reforma educativa). Y por eso no es baladi que el partido que sustenta al Gobierno mantenga la mayoría en la Mesa de las Comisiones, por sí solo o con sus socios de legislatura ${ }^{56}$.

55. El hecho de que la gran mayoría de las iniciativas legislativas no llegue, en Italia, a la deliberación definitiva de la Cámara es debido, según Sandoulu ("Legge", cit., pág. 638) a la imposibilidad material, y no a que no exista una obligación de tramitación que pese sobre la Cámara. Se debe a la acumulación de iniciativas en las Comisiones, con la consecuencia de que su iter acaba por ser determinado por acuerdo entre los Grupos parlamentarios, que no siempre resulta conforme a las exigencias de una correcta programación legislativa. A. MANZFLLA ("Note sull' organizzazione dei lavori parlamentari", cit., pág. 7) dice que "el calendario de trabajo en las Comisiones se rige hoy por criterios ocultos".

56. También en Italia, la fijación del orden del día puede jugar positiva o negativamente, y según como se ejercite constituye un instrumento de importancia relevante sobre la suerte de la iniciativa en sede parlamentaria (F. Cuocolo, Saggio sulliniziativa legislativa, cit., pág. 111). En la práctica, la falta de normas reglamentarias precisas se suple con reuniones informales de los portavoces de la mayoría, que acuerdan los proyectos a incluir en el orden del día de cada Comisión. Esta práctica 
Pero incluso en el caso de que el Presidente de la Comisión pertenezca a la oposición, la mayoría parlamentaria dispondrá de otros instrumentos idóneos para dirigir las decisiones, que en concreto en materia de orden del día corresponde a la Mesa de la Comisión.

Resumiendo, pues, la duración del procedimiento en el Congreso para la tramitación de los proyectos y proposiciones de ley dependerá del impulso de la mayoría, que puede llegar a tramitar un proyecto en una o dos semanas, o mantenerlo intocado hasta el final de la legislatura, con la consiguiente caducidad de la iniciativa.

Como decíamos antes, la doctrina suele reducir el examen de la prioridad debida de los proyectos de ley a una cuestión temporal, es decir, una preferencia en la tramitación (en la inclusión en el orden del día), de los proyectos sobre las proposiciones de materia similar.

Así, Santamaría Pastor ${ }^{57}$ centra su atención sobre los problemas que surgen cuando se presentan proposiciones sobre la materia contenida en un proyecto de ley en sus distintas fases de tramitación (en algunas de ellas se plantea la inadmisión de las iniciativas), y a la inversa, cuando se presentan proyectos estando en trámite una proposición similar ${ }^{58}$. Concluye este autor considerando que el precepto constitucional incurre en error técnico por la complejidad procedimental que introduce.

La realidad es más sencilla que todo eso. Proyectos y proposiciones siguen su iter separado aunque versen sobre la misma cuestión. Ello quiere decir que normalmente, de acuerdo con las reglas señaladas para la inclusión en el orden del día, un proyecto se adelantará a una proposición presentada en las mismas fechas, salvo que haya interés en tomarla en consideración para acumular su tramitación a la del proyecto.

Obviamente, para desactivar una proposición de ley de la oposición sobre una materia necesitada de regulación, el Gobierno puede: a) presentar un proyecto con

es criticada por LuCIFREd (L'iniziativa legislativa parlamentare, cit., pág. 166), que lamenta que los Presidentes de las Comisiones se vean así desautorizados de unas prerrogativas que constitucionalmente les competen sin duda. F. Cuocolo, ibidem, pág. 112, por contra, no cree criticable el intento de poner orden en una situación de otro modo destinada a ser regulada por la improvisación de decisiones contingentes (puesto que las decisiones de los Presidentes son apelables ante las Comisiones, con resultados no siempre predecibles). Si no cuenta el Gobierno con mayoría en la Comisión, el Presidente podrá apartarse más fácilmente de la línea seguida o sugerida por el Ejecutivo, con evidentes consecuencias negativas para la política del Gobierno, condicionada a la formación de mayorías contingentes y mutables, y por tanto con la imposibilidad de obtener con seguridad los instrumentos legislativos que considera necesarios. Se trata de situaciones patológicas y de duración necesariamente limitada, que interesan sólo marginalmente a la fase de iniciativa del procedimiento de formación de las leyes (págs. 112-113).

57. J. A. Santamaría Pastor, "Comentario al artículo 89", cit., págs. 1278-1280.

58. La prioridad del proyecto podría dar lugar, según J. F. MERINo MERCHÁN, a que el Gobierno dispusiera de un arma para eliminar todas aquellas proposiciones que considera molestas para su estabilidad y su programa. También este autor propone una serie de reglas para interpretar racionalmente el principio de prioridad debida en caso de presentación de proyectos y proposiciones con idéntico objeto ("Rasgos definidores de la iniciativa legislativa prevista en el artículo 87 de la Constitución", cit.; págs. 55-57). 
su visión de la materia y hacer que la mayoría rechace la toma en consideración de la proposición; b) presentar asimismo un proyecto para que se tramite acumuladamente con la proposición tomada en consideración y obtener así una regulación diferente a si ésta fuese tramitada en solitario, con lo que se desvirtúa en parte la iniciativa no gubernamental ${ }^{59}$.

También puede detenerse la tramitación de una proposición tomada en consideración para esperar a que un proyecto recién presentado esté en condiciones de acumulación, o simplemente, para siempre, mientras que el proyecto se tramita, aunque esto será poco probable si lo que se desea es concitar acuerdos en torno al mismo.

Las posibilidades son variadas y no merecen mayor atención. Baste con concluir que el Gobierno dispone, a través de la mayoría parlamentaria, de armas que le permiten asegurar la prioridad temporal debida a los proyectos de ley sobre las proposiciones que pretenden simultáneamente la regulación sobre la misma materia.

\subsection{La agilización del procedimiento: declaración de urgencia y sesiones extraordinarias}

Al describir los mecanismos introducidos por nuestra Constitución en el proceso de producción de la ley para fortalecer la posición del ejecutivo frente a posibles entorpecimientos del iter legis, Garrorena Morales formula el uprincipio de agilización procesal", que junto con el "principio de prioridad procesal" debida a los proyectos de ley, permiten dotar con eficacia al Gobierno del derecho que necesita ${ }^{60}$. Creemos que, más que como principio independiente, podemos encuadrar los poderes de agilización procesal en manos del Gobierno como una manifestación más del principio de prioridad reconocido en la Constitución.

El autor antes citado engloba en el principio señalado las vías abiertas por los artículos 90.3 (urgencia) y 75.2 (delegación en Comisión) a la simplificación de trámites y abreviación de plazos, destacando que se trata de técnicas que tienden a incidir sobre el procedimiento desobstruyéndolo, pero no sobre la decisión final, que permanece en plenitud bajo soberanía parlamentaria, manteniendo pues la elevada posición institucional del Parlamento y de la legalidad.

Aquí vamos a adoptar una óptica ligeramente distinta. Bajo la rúbrica de agilización procesal, como manifestación de la prioridad debida a los proyectos de ley, estudiaremos las posibilidades abiertas al Gobierno para agilizar la tramitación de los proyectos de ley; es decir, los casos en los que la Constitución o los Reglamentos le atribuyen la facultad de actuar sobre el procedimiento para acortar los plazos o aligerar su tramitación.

59. No olvidemos que puede tratarse de una sola o de varias proposiciones de distintos sujetos tomadas en consideración sobre el mismo objeto.

60. A. Garronina Morales, El lugar de la ley en la Constitución española, cit., págs. 114-115. 
No nos referimos, por tanto, al procedimiento descentralizado en Comisión (del que nos hemos ocupado ya en otro lugar) ${ }^{61}$ porque, por mucho que el Gobierno pueda actuar a través de la mayoría que le apoya, no está en su mano instarlo ni acordarlo. Lo mismo ocurre con el procedimiento de lectura única, previsto en los artículos $150 \mathrm{RC}$ y $129 \mathrm{RS}^{62}$, también de reducción temporal o abreviado, pero que se acuerda por el respectivo Pleno de la Cámara a propuesta de la Mesa, oída la Junta de Portavoces. El Gobierno podrá, en su caso, efectuar una sugerencia o solicitud en tal sentido, pero que podrá ser o no atendida, careciendo de facultad alguna al respecto.

En cambio, si debemos incluir en este epígrafe los poderes del Gobierno en relación con las sesiones extraordinarias, pues ello le permitirá evitar los aplazamientos que el fin del periodo de sesiones marca para la aprobación de los textos legislativos.

\section{a) El procedimiento de urgencia}

De los procedimientos abreviados, el más característico y general es el procedimiento de urgencia ${ }^{63}$. En efecto, el procedimiento desconcentrado en Comisión, que también puede ser contemplado desde el prisma de la abreviación de trámites, tiene limitadas por el artículo 75.3 de la Constitución las materias sobre las que puede recaer; y el procedimiento de lectura única, contrario al anterior en cuanto que el trámite que suprime es el de Comisión (mientras que en aquél es el de Pleno), debe aplicarse sólo ${ }^{64}$, según los artículos 150 RC y 129 RS, a proyectos cuya "naturaleza lo aconseje o su simplicidad de formulación lo permita.

La tramitación por urgencia cabe, por el contrario, para cualquier proyecto o proposición de ley. Se trata además de un procedimiento de abreviación estrictamente temporal, en cuanto actúa exclusivamente sobre los plazos establecidos con carácter general para reducirlos a la mitad, sin supresión ni modificación de trámites. Su sencillez hace, por tanto, que sea el procedimiento abreviado más utilizado.

61. Recordemos, no obstante, las críticas que se han formulado a la deficiente formulación del Reglamento del Congreso de los Diputados en este punto, que en España no ha alcanzado el volumen de aprobación de las leyes por este procedimiento en que se sitúa en Italia (dos tercios de la legislación estatal), ni otros efectos negativos criticados en ese país (véase A. Ruz Rolililio, "La delegación legislativa en las comisiones parlamentarias", cit., pág. 100). No cabe hablar aquí de "desarticulación del Parlamento" como lo hacía MorTati (Istituzioni di diritto pubblico, 8." ed. Padova, 1969, I, pág. 747).

62. R. Punset ("La fase central del procedimiento legislativo", cit., pág. 131) plantea la duda sobre la constitucionalidad del artículo 129.4 RS, en cuando considera rechazado por la Cámara el proyecto o proposición que no sea aprobado por el Senado o no alcance la mayoria exigida según la naturaleza del proyecto. Entiende que el artículo 90.2 no contempla un mero rechazo, sino un veto.

63. Mencionado dos veces en el texto constitucional, en los artículos 86.3 (tramitación de los decretos leyes convalidados por el procedimiento de urgencia) y 90.2 (reducción de plazo de tramitación de los proyectos en el Senado).

64. Otra cosa es que pueda aplicarse en la práctica a otros proyectos, o que esté previsto en ocasiones para leyes "pactadas", como las modificaciones de la LORAFNA o los acuerdos sobre concierto y cupo económico con las Comunidades Autónomas de Navarra y País Vasco. Ya nos hemos pronunciado en contra de este tipo de leyes, por su incidencia negativa sobre la soberanía legislativa de làs Cámaras. 
A diferencia del procedimiento de lectura única, el de urgencia tiene apoyatura constitucional, pues el artículo 90.3 se refiere a "los proyectos declarados urgentes por el Gobierno o por el Congreso de los Diputados", bien que para fijar sus efectos sólo en cuanto a la actuación del Senado: el plazo de dos meses de que dispone para vetar o enmendar el proyecto se reduce al de veinte días naturales.

El Reglamento del Congreso no contempla un procedimiento de urgencia como tal. Se limita a incluir un capítulo ("De la declaración de urgencia") entre las disposiciones generales de funcionamiento. Dicha declaración tiene como efecto la reducción a la mitad de los plazos establecidos con carácter ordinario. Ahora bien, de una parte se salva la facultad reconocida a la Mesa en el artículo 91 de acordar la prórroga o reducción de los plazos; de otra parte, la escasa fijación de plazos para las distintas fases del procedimiento en el Congreso (apenas quince días para la presentación de enmiendas ${ }^{65}$, quince días ampliables para la elaboración del informe de la Ponencia, y dos meses, asimismo ampliables y escasamente observados, para la tramitación de cualquier asunto por una Comisión -artículo $43.2 \mathrm{RC}-$ ), hace que la tramitación de un proyecto o proposición en el Congreso no tenga una duración fija o media. De ahí que las consecuencias de la reducción a la mitad de los plazos tenga consecuencias muy relativas en esta Cámara, aunque sí pueden servir a la mayoría de la Mesa para apoyar la eventual denegación de la ampliación del plazo de enmiendas o a la mayoría pura y simple para justificar su inclusión apresurada en el orden del día del Pleno.

Donde surte efectos reales la declaración de urgencia, por imperativo constitucional, es en el Senado. De ahí que su Reglamento prevea un procedimiento específico para conseguir tramitar un proyecto o proposición en los veinte días naturales que le permite la Constitución, con plazos tan breves como el de cuatro días naturales (ampliables sólo una vez, por otros dos días) para la presentación de enmiendas. La rigidez de este procedimiento (en cuanto al cómputo de plazos en días naturales) hace que en ocasiones sea preferible optar por un procedimiento intermedio o de semiurgencia, previsto en el Reglamento del Senado para cuando no se declare la urgencia pero interese reducir la tramitación a un mes, reduciéndose a la mitad los plazos establecidos para el procedimiento ordinario. El simple hecho de que, como en éste, se computen los plazos en días hábiles y no en naturales como en el procedimiento de urgencia, alivia la tensión temporal y permite un poco de mayor sosiego en la tramitación. De ahí que, de forma consensuada con el Gobierno (para que no declare la urgencia), se haya aplicado en los últimos años este procedimiento a la tramitación del proyecto de Ley de Presupuestos Generales del Estado, cuando la aprobación algo más temprana por el Congreso ha permitido ampliar en unos días su paso por el Senado ${ }^{66}$.

65. Frente a la rigidez con que actúa el vencimiento de los plazos en el Senado, en la Cámara Baja incluso se subsana la presentación tardía de enmiendas y votos particulares con la aquiescencia de los grupos a su tramitación, manifestada en Junta de Portavoces.

66. No así para el proyecto de la llamada Ley de acompañamiento, que al no tener urgida por la Constitución su aprobación en tres meses, como la Ley de Presupuestos (arts. 134.3 y 4), es declarada urgente para que su tramitación se acompase a la de aquélla, con la consecuencia de la aplicación del procedimiento de urgencia en el Senado. 
Más que los efectos sobre los plazos de la declaración de urgencia nos interesa conocer cuáles son las facultades del Gobierno en este punto, que puede utilizar para conseguir la tramitación acelerada (al menos, como hemos visto, en el Senado, pero también en el Congreso si hay consenso o voluntad de la mayoría) de un proyecto. Hemos visto que la Constitución atribuye esta declaración al Gobierno y al Congreso de los Diputados (art. 90.3), sentando sus efectos sobre la duración de la tramitación en el Senado.

El reconocimiento constitucional de la posición del Gobierno es plenamente coherente con el principio de cooperación legislativa, propio de un régimen parlamentario, en el que la autonomía de las Cámaras no obsta a que se dote al Gobierno de los medios necesarios para el desarrollo de su función de dirección política (art. 97) mediante instrumentos legislativos.

Cuando una medida política que requiere su adopción en breve plazo requiere de su regulación por ley, la declaración de urgencia permite al Gobierno asegurarse una más rápida tramitación, con certeza en cuanto a los plazos en la segunda Cámara.

Son diversas las circunstancias que pueden motivarla: inexcusable cumplimiento de una obligación internacional, medidas no adoptables por Decreto-ley (por ser a medio plazo, por ejemplo) para atender o prevenir catástrofes, proximidad del fin de la legislatura o incluso del período de sesiones..., todas ellas pueden mover al Gobierno a declarar la urgencia de un proyecto de ley.

Esta declaración no ha sido regulada por la Ley del Gobierno, la cual únicamente alude a razones de urgencia para prescindir de la segunda lectura del proyecto en Consejo de Ministros, sin perjuicio de la emisión de los informes de carácter preceptivo (art: 22.5).

La declaración por el Gobierno, prevista en la Constitución, como hemos visto, afecta a la tramitación de los proyectos en la Cámara Alta ${ }^{67}$. Concorde con la atribución de la facultad de declaración también al Congreso de los Diputados, su Reglamento ha previsto que la Mesa pueda acordar que un asunto se tramite por procedimiento de urgencia en esta Cámara a petición del Gobierno, de dos Grupos parlamentarios o de una quinta parte de los Diputados. Por tanto, si el

67. No hay unanimidad en la doctrina en cuanto a que la declaración de urgencia por el Gobierno no afecta a la Cámara Baja, donde ha de solicitar la declaración por la Mesa. En favor de esta postura, F. SANTAOLALla López, "Artículo 90: intervención legislativa del Senado", Comentarios a las leyes políticas. Constitución Española de 1978, tomo VII, Edersa, Madrid, 1983-1989, págs. 340-344, y M:" A. García Martínez, El procedimiento legislativo, cit., págs. 301. En contra, J. A. Santamarí Pastor, para quien es patente la contradicción entre el artículo 93.1 del Reglamento del Congreso y el artículo 90.3 de la Constitución, no existiendo razones institucionales serias para defender la posibilidad de que el Gobierno pueda declarar la urgencia respecto de los trámites en una Cámara y no en la otra ("Comentario al artículo 90", Comentarios a la Constitución, dirigidos por F. Garrido Falla, 2." ed, pág. 1291). Tal vez sea esta la posición más correcta. Sin embargo, y pese a que un informe de la Secretaría General del Congreso admite la declaración por el Gobierno, con los efectos previstos en los artículos 93.2 y 94 RC («Nota de la Secretaría General del Congreso de los Diputados relativa a la declaración de urgencia en la tramitación de los proyectos de ley", en Revista de las Cortes Generales, n. ${ }^{\circ}$ 27, 1992 , pág. 161), la práctica, al menos última, muestra que la Mesa decide siempre sobre la solicitud del Gobierno. 
Gobierno desea que el acortamiento de los plazos se produzca también en la primera fase de la tramitación en las Cortes, deberá solicitar de la Mesa del Congreso la declaración de urgencia.

Esta solicitud puede hacerse desde la remisión del proyecto, acordándose en el mismo Consejo de Ministros en que se aprueba aquélla, en cuyo caso se hace constar en el oficio de remisión y se acompaña certificación del acuerdo.

La Mesa del Congreso viene exigiendo la motivación de la solicitud, al objeto de poder decidir con fundamento sobre la misma, de forma que no se pronuncia en los casos de ausencia de motivación y requiere aclaración cuando aquélla le parece insuficiente.

De adoptar la Mesa el acuerdo de tramitación por el procedimiento de urgencia (como dice el artículo 93.1 RC) desde la admisión a trámite del proyecto, el plazo inicial de enmiendas se reducirá a la mitad (ocho días), lo que no impide eventuales ampliaciones posteriores. Si el acuerdo se adoptara iniciada la tramitación del proyecto, "el procedimiento se aplicará a los trámites siguientes" (art.s 93.2 $\mathrm{RC}$ ), lo que en definitiva no supondrá gran diferencia, en cuanto a la duración del procedimiento en el Congreso, por las circunstancias antes señaladas.

Pero sí tendrá la virtualidad de que resulte de aplicación el artículo 90.3 de la Constitución y se acorte el procedimiento en el Senado a veinte días naturales. En esta Cámara, además de la previsión de la declaración de urgencia de los proyectos por el Gobierno o por el Congreso, la Mesa puede asimismo decidir, de oficio o a propuesta de un Grupo parlamentario o de veinticinco senadores, la aplicación del procedimiento de urgencia. Es en este caso una disposición reglamentaria, producto de la autonomía de la Cámara, la que permite a la Mesa del Senado adoptar este acuerdo, a diferencia del Congreso que, al igual que el Gobierno, tiene atribuida la facultad de declaración de urgencia por la Constitución.

En relación con esta cuestión, se ha producido un incidente -artificioso, por otra parte- que terminó con la interposición de un conflicto de competencias por el Gobierno ante el Tribunal Constitucional. Remitido por el Congreso de los Diputados al Senado el proyecto de ley orgánica de ampliación de los supuestos de interrupción voluntaria del embarazo, estando próxima la finalización de la V Legislatura, la Mesa de la Cámara rechazó la solicitud del Gobierno de declaración de urgencia para su tramitación ${ }^{68}$, por entender que el Gobierno carece de competencia para declarar la urgencia en ese momento procedimental, si no la había declarado previamente al aprobar el proyecto de ley y remitirlo al Congreso de los Diputados.

No creemos que en este punto estuviera acertada la Mesa del Senado ${ }^{69}$, cuya mayoría adoptó una táctica dilatoria por motivos políticos, contraria a la práctica

68. Acuerdos de 30 de noviembre y 12 de diciembre de 1995.

69. Sobre el incidente en general, véase E. ARANDA Álvarez, "Tres casos difíciles en la fase del Senado del procedimiento legislativo", Revista de las Cortes Generales, n. ${ }^{\circ} 39$, 1996, págs. 164-169, con la advertencia expresa y formal de que no coincidimos en absoluto con las tesis del autor respecto de las competencias del Senado expresadas para los dos primeros casos examinados (caso "Ses Salines" y caso "Ley de ordenación del comercio minorista", sobre las facultades de aprobación y de enmienda de la Cámara Alta). Véase también F. SANTAOLALLA LópEz, "Artículo 90: intervención legislativa del Senado", cit., págs. 414-415. Este autor cree posible entender que los proyectos recibidos del Congreso no 
hasta entonces seguida, que no había planteado ningún obstáculo a supuestos similares. No parece haber elementos en el artículo 90.3 de la Constitución que apoyen la limitación de la declaración de urgencia por el Gobierno a un primer momento, tanto menos cuanto que, para la tesis más restrictiva, sus efectos sólo alcanzarían al Senado.

Ante el rechazo del requerimiento formulado por el Gobierno a la Mesa del Senado, aquél presenta conflicto de competencias (4476/1995) contra el Senado, pendiente de resolución por el Alto Tribunal. Esperemos que su decisión en este evitable incidente, como en otros recursos planteados ${ }^{71}$, no repercuta innecesariamente sobre la de por sí menguada posición del Senado en el procedimiento legislativo.

Con esta reflexión concluimos el examen de la declaración de urgencia como medio en manos del Gobierno para agilizar la tramitación de los proyectos, que constituye una manifestación más de la prioridad que la Constitución le reconoce para poner en práctica su programa legislativo.

\section{b) Las sesiones extraordinarias}

En la misma dirección de agilización y acortamiento de la duración del procedimiento legislativo se situaría la facultad, atribuida al Gobierno por el artículo 73.2 de la Constitución, de pedir la reunión de las Cámaras en sesiones extraordinarias. Si hemos señalado como una de las causas de la declaración de urgencia la proximidad de la finalización del período de sesiones, aquí sería el hecho de tal finalización y la inactividad de las Cámaras durante el período intersesiones lo que actuaría como motor del ejercicio por el Gobierno de su facultad.

Recordemos que el Parlamento es un órgano permanente de funcionamiento discontinuo, existiendo periodos en el año (julio, agosto y enero) en los que normalmente no actúa, tanto para que los parlamentarios atiendan a sus circunscripciones, como para que el Gobierno pueda trabajar con sosiego sin atender a los constantes requerimientos de presencia e información de las Cámaras.

La Constitución, al fijar los períodos ordinarios de sesiones (septiembre a diciembre y febrero a junio, siguiendo una cronología similar a la del curso escolar) prevé la posibilidad de sesiones extraordinarias ${ }^{71}$, que no períodos de sesiones extraordinarias, que deberán convocarse sobre un orden del día determinado y ser clausuradas una vez agotado aquél.

están en el ámbito de la capacidad dispositiva del Gobierno, pero a la vez considera que el artículo 133 RS ("En los proyectos declarados urgentes por el Gobierno o por el Congreso de los Diputados...") era de observancia obligada para la Mesa del Senado.

70. Los dos citados en la nota anterior, por ejemplo, y otros sobre las facultades de enmienda del Senado, como el recurso contra la Ley 50/1998, de 30 de diciembre, de Medidas fiscales, administrativas y del Orden social para 1999.

71. Y no períodos extraordinarios de sesiones, como preveía el artículo 65.2 del Anteproyecto de Constitución. 
La Constitución atribuye la facultad de "pedim sesiones extraordinarias al Gobierno, la Diputación Permanente y la mayoría absoluta de miembros de cualquiera de las Cámaras. No debe malinterpretarse el verbo utilizado: la solicitud realizada por un sujeto legitimado vincula al Presidente de la Cámara a la convocatoria del órgano para el que se solicita (Pleno, Comisión o incluso Ponencia, en la práctica parlamentaria) para el orden del día señalado.

Así como la atribución a la Diputación Permanente y a la mayoría de la Cámara de la disposición sobre las sesiones extraordinarias va dirigida a servir los propios intereses de aquélla, normalmente centrados en torno al control del Gobierno, el incluir a éste entre los sujetos legitimados para instar la celebración de sesión extraordinaria responde al parlamentarismo cooperativo del que hemos hablado, en que el Gobierno puede tener razones para que se reúna la Cámara entre sesiones: además de, por ejemplo, poder querer comparecer ante el Parlamento para exponer situaciones de importancia -frecuentemente de ámbito internacional-, se encuentra la necesidad de llevar a cabo su programa sin quedar detenido uno o varios meses por estar pendiente de decisión de las Cámaras.

Así, las solicitudes de sesión extraordinaria para tramitar textos legislativos (bien sólo en Pleno, bien en las fases anteriores del procedimiento) son frecuentes, mucho más cuando se prevé que las Cámaras no reanudarán su labor en un próximo período de sesiones, por quedar disueltas antes de que se inicie.

Precisamente porque la facultad del Gobierno va unida a un fin concreto, relacionado con sus funciones e intereses, es criticable que se haya utilizado recientemente para instar la reunión extraordinaria de una Comisión de Investigación ${ }^{72}$, instrumento de control en el que la Cámara debe tener plena autonomía de funcionamiento, por mucho que el Gobierno pueda solicitar su creación ( $52 \mathrm{RC}$, 59.1 RS). Sería como si el Gobierno solicitara una sesión extraordinaria de una de las Comisiones "internas" de las Cámaras, las llamadas Comisiones Generales, como son la de Estatuto del Diputado (Incompatibilidades y Suplicatorios en el Senado) o Reglamento.

Como decíamos, la práctica ha generalizado lo que se conoce con el nombre de "pleno-escoba" en el mes de julio, sobre todo para aquellos proyectos aprobados por el Senado y pendientes únicamente de aceptación o rechazo de sus enmiendas por el Congreso. Igualmente, es relativamente frecuente la «habilitación del mes de enero" o, lo que es más correcto, la celebración de sesiones extraordinarias en el mes de enero para que una Comisión de una u otra Cámara ultime su dictamen sobre algún proyecto o lo apruebe con competencia plena.

72. Solicitud de celebración de sesión extraordinaria (incorrectamente presentada como "solicitud de habilitación del mes de julio" de 1998 "para que pueda reunirse") de la Comisión de Investigación para analizar la política desarrollada mediante ayudas comunitarias al cultivo del lino en el marco de la política agraria común, censurable también por la indeterminación del orden del día de la sesión a celebrar. Afortunadamente, la mayoría de los miembros de la Cámara, conscientes de lo anómalo de la solicitud, han presentado también una petición de convocatoria de dos sesiones extraordinarias de lá misma Comisión, acumulable a la primera. 


\subsection{Otros factores favorables a la prioridad de los proyectos de ley}

Concluimos aquí el examen de las manifestaciones de la prioridad debida a los proyectos de ley que van surgiendo a lo largo del procedimiento legislativo. No nos queda sino hacer una referencia general a la especial posición que ocupan los proyectos de ley, por provenir del Gobierno, en relación con la mayoría que apoya a éste, que origina una prioridad de facto motivada por circunstancias diversas, como las siguientes:

- Enmiendas presentadas por el grupo mayoritario elaboradas por el propio Gobierno y de otros grupos afines negociadas con él.

- Ponencia compuesta en su mayoría por miembros de los grupos que apoyan al Gobierno, que le consultan sobre la admisión de enmiendas, siendo en último término su voluntad la que prima en esta fase fundamental del procedimiento ${ }^{73}$.

- Presidente de Comisión o mayoría de la Mesa de la Comisión que, como hemos señalado al estudiar la inclusión en el orden del día, aligera o retarda la tramitación de proyectos y proposiciones.

- Mayoría en la Junta de Portavoces para incluir el proyecto de ley en la sesión plenaria que interese al Gobierno.

\section{LA ESPECIAL PRIORIDAD DEL PROYECT.O DE LEY DE PRESUPUESTOS}

La primera especialidad de la iniciativa presupuestaria es que está reservada al Gobierno. Desde la perspectiva de este trabajo, observaremos que el proyecto de Ley de Presupuestos es el único que tiene fijado por la Constitución su calendario de presentación y aprobación (apartados 3 y 4 del artículo 134 de la Constitución). Ello provoca que los Reglamentos tengan que establecer un procedimiento especial para su tramitación, y que los de ambas Cámaras declaren tajantemente que el proyecto de Ley de Presupuestos Generales del Estado gozará de preferencia en la tramitación con respecto a los demás trabajos de la Cámara (133.2 RC, 148.1 RS).

La determinación por la Constitución del momento de presentación del proyecto por el Gobierno ante el Congreso de los Diputados al menos tres meses antes de la expiración de los presupuestos del año anterior y la previsión de prórroga automática de los presupuestos del ejercicio anterior si no se ha aprobado la Ley de Presupuestos antes del primer día del ejercicio económico correspondiente, implican que la duración de la tramitación del proyecto queda reducida a

73. Sobre lo que es y debería ser la fase de ponencia, véase J. A. SANTAMaría Pastor, uLas ponencias como instrumento del trabajo parlamentario", en Anuario de Derecho Constitucional y Parlamentario, n. ${ }^{\circ}$ 6, 1994, págs. 57-75, y A. L. Alonso DE ANTONIO, "Las ponencias en el procedimiento legislativo", El procedimiento legislativo, V Jornadas de Derecho Parlamentario, Congreso de los Diputados, Madrid, 1997, págs. 421-467. 
tres meses, del 1 de octubre ${ }^{74}$ al 31 de diciembre de cada año, de los cuales grosso modo dos meses corresponden a la tramitación en el Congreso (incluido el pronunciamiento final sobre las enmiendas del Senado) y un mes en el Senado.

Recoder de $\mathrm{Casso}^{75}$ considera infundada la queja sobre la premura con que las Cámaras han de pronunciarse sobre materia tan importante y compleja, recordando que salvo en el caso americano, peculiar por su propio sistema de Gobierno, en ningún otro país dispone el Parlamento de plazos más amplios para el debate presupuestario.

De otra parte, tampoco dedicarían las Cámaras más tiempo real (otra cosa es el tiempo de permanencia de los proyectos en el Congreso) al estudio de otros proyectos de ley. Finalmente, el hecho de que la Ley de Presupuestos se debate cada año significa que los miembros de la Comisión no pueden alegar ignorancia del tema que se regula, y que pueden dedicar tiempo el resto del año a la preparación del debate que se producirá inevitablemente en el último trimestre.

Es en el Senado donde sí se produce una restricción del tiempo normal de tramitación, si se produce la declaración de urgencia, inevitable por ser hábiles en el mes de diciembre en realidad los primeros veinte días, dadas las fiestas navideñas de la última decena y la necesidad de incluir en ella ese pronunciamiento del Congreso sobre las enmiendas de la Alta Cámara.

No obstante, desde hace algún tiempo, se consigue adelantar mínimamente la aprobación por el Congreso en torno al veinte de noviembre, lo que permite la tramitación en el Senado por el procedimiento de semi-urgencia previsto en el artículo 136 del Reglamento, con el beneficioso efecto de cómputo de plazos en días hábiles (y no naturales, como en el de urgencia), que alivia algo la presión, sobre todo en cuanto a la presentación de enmiendas.

De las especialidades en la tramitación del proyecto de Ley de Presupuestos sólo nos interesan aquí las derivadas de la prioridad reglamentariamente consa$\operatorname{grada}^{76}$. Algún autor la interpreta en el sentido de que durante el tiempo que la ley está en el Parlamento nada puede entorpecer su estudio, de forma que, en caso de entrar en competencia de cualquier tipo (por ejemplo, necesidad de salas

74. En los últimos años, el Ministro de Hacienda tiene a gala adelantar unos días la entrega del proyecto a las Cortes, caso insólito de no agotamiento del plazo, que hace realidad el "al menos" constitucional. Sobre los efectos del incumplimiento del plazo por el Gobierno, L. Cazorla Pritto (Comentario al artículo 134.3", Comentarios a la Constitución, dirigidos por F. Garrido Falla, 2." edición, Civitas, Madrid, 1985, pág. 1999) opina que serían de carácter político, que no afectarián a la eficacia jurídico-parlamentaria del acto de remisión. Por el contrario, E. Reconfr cree que en caso de demora por el Gobierno en el cumplimiento de su obligación constitucional, las Cortes podrán consumir legítimamente tres meses en el debate, cesando para ellas la obligación de no dejar terminar el ejercicio sin aprobación, tanto en virtud de un mecanismo similar al que rige en las obligaciones recíprocas en el Derecho privado (art. 1100 del Código Civil), como en último término, en el respeto a la voluntad del constituyente de reservar al Parlamento al menos tres meses para examinar, enmendar y aprobar los presupuestos ( Iniciativa legislativa presupuestaria", Presupuesto y Gasto Público, n. ${ }^{\circ}$ 18, 1983, pág, 254).

75. E. RrConer de CAsso, Ibidem, págs. 152-153.

76. Recuérdese que serán estas especialidades procedimentales y, en particular, la limitación temporal, las que han llevado al Tribunal Constitucional a delimitar el contenido material de la Ley de Presupuestos frente a su tendencia expansiva. 
de reunión) con otros proyectos, sus exigencias deben ser atendidas prioritariamente $^{77}$. Pero creemos que existen algunas manifestaciones concretas de esa prioridad, o del fundamento que la inspira, a saber, la obligación del cumplimiento del plazo constitucional de tres meses para la tramitación del proyecto.

- En este sentido, en primer lugar, es el único proyecto de ley para el que las Mesas de las Cámaras aprueban un calendario de tramitación, publicado en el Boletín Oficial de las Cortes Generales, acompañado de unas reglas especiales como la habilitación de días y horas precisos para la celebración de las sesiones de Ponencia y Comisión y reglas para la presentación de enmiendas, como son: establecer que en los dos últimos días de los plazos señalados para la formulación de las solicitudes de comparecencia y para la presentación de enmiendas, esta presentación sólo podrá tener lugar ante el Registro General de la Cámara y dentro del horario ordinario del $\operatorname{mismo}^{78}$ y requerir, como condición de admisión a trámite, que las enmiendas que se presenten indiquen, necesariamente, no sólo el crédito a que afectan dentro de cada sección, sino también el programa o programas en los que vienen a incidir.

- En este calendario, se reserva una semana en el Congreso (al igual que en el Senado, aunque previa a la entrada del proyecto en la Cámara) ${ }^{79}$ para la celebración de comparecencias de autoridades y funcionarios que permitirán obtener información para pronunciarse sobre los créditos cuya autorización se solicita. Durante el tiempo reservado a este fin no se celebran reuniones de otras Comisiones, para no impedir la labor del elevado número de parlamentarios de los distintos grupos que actúan como ponentes de sus grupos respecto de alguna de las Secciones del proyecto.

- No parece que sean admisibles, y esto no por razones de prioridad, sino de ámbito reservado a la iniciativa del Gobierno ${ }^{80}$, las enmiendas a la totalidad de texto alternativo, que serían tanto como suplantar al Gobierno en la competencia sobre la elaboración del proyecto que le atribuye el artículo 134.1 de la Constitución. Por la misma razón de competencia constitucional, esta vez de las Cortes Generales, sobre el examen, enmienda y aprobación de los Presupuestos Generales del Estado, quedan excluidos de la delegación legislativa en Comisión (art. $75.3 \mathrm{CE}$ ).

- El plazo para la presentación de enmiendas se aplicará con mayor rigor que respecto de otros proyectos, fijándose de antemano en el calendario de tramitación (incluso antes de que entre el proyecto en la Cámara) y admitiéndose como mucho una breve ampliación, frente a las múltiples usuales en otros proyectos ${ }^{81}$.

77. E. RfCODER DE CASso, "Iniciativa legislativa presupuestaria", cit., págs. 153.

78. Para evitar los retrasos en la llegada de enmiendas presentadas por correo. Disposiciones similares se adoptan en el calendario para la tramitación en el Senado.

79. En el Senado, las comparecencias tiene lugar con anterioridad a la entrada del proyecto en la Cámara, tanto debido al escaso tiempo de que se dispone para su tramitación, como porque la información de ellas obtenida sirve para la confección de las enmiendas que se presenten al proyecto.

80. Véase supra, objeto y limites.

81. Existen otras especialidades procedimentales en relación con las enmiendas, en las que no nos detenemos porque no derivan de la prioridad de los presupuestos: las relativas a las que supongan 
- La fecha de las sesiones plenarias dedicadas al debate del proyecto de Ley de Presupuestos queda fijada con antelación cuando se aprueba el calendario del correspondiente período de sesiones. Se trata de Plenos específicos, no monográficos, puesto que pueden debatirse en los mismos algunos proyectos que acompañen al de Presupuestos (la llamada Ley de acompañamiento, pero también otros proyectos relacionados con la política económica que deben iniciar su vigencia, como aquél, el 1 de enero ${ }^{82}$ ), e incluso otros proyectos que conviene aprobar antes de que finalice el año ${ }^{83}$. Pero el debate, en una y otra Cámara, y aquí sí por su carácter prioritario, se inicia siempre con el proyecto de Ley de Presupuestos, y a su duración se subordinan los restantes puntos del orden del día.

Se trata de cuatro sesiones plenarias:

a) La primera será aquella sesión del Congreso de los Diputados en que se celebre el debate de totalidad, en la última semana de octubre, en el que, según el artículo 134.1 RC, quedan fijadas las cuantías globales de los estados de los Presupuestos. La práctica demuestra que esto no es así, y que aquellas cuantías variarán por la admisión de enmiendas en Comisión y en Pleno, por mucho que se exija una baja en la misma sección ${ }^{84}$. La prueba es que nunca se votan en el Congreso las cifras globales de los presupuestos, autorizándose (según declara el Presidente al final del debate del articulado) a los servicios jurídicos de la Cámara la realización de los ajustes técnicos necesarios ${ }^{85}$.

b) La segunda, en el Congreso de los Diputados, a finales del mes de noviembre, iniciándose normalmente en lunes frente al martes inicial de las sesiones ordinarias semanales, y excluyendo la aplicación del artículo 111 de la Constitución (conforme al cual, para el debate de interpelaciones y preguntas, los Reglamentos establecerán un tiempo mínimo semanal), traducido por el artículo $191 \mathrm{RC}$ como "las semanas en que exista sesión ordinaria del Pleno se dedicarán, por regla general, dos boras como tiempo minimo a preguntas e interpelaciones". Se rompe, pues, el esquema de las sesiones semanales que examinamos en relación con el orden del día, tratándose exclusivamente asuntos legislativos, con el predominio absoluto y la prioridad temporal del proyecto de Ley de Presupuestos, que se debate en primer lugar.

c) Lo mismo ocurre en la sesión plenaria a celebrar en el Pleno del Senado, a finales del mes de diciembre, en la semana misma de las festividades navideñas

aumento de créditos, que requieren la propuesta de una baja en la misma sección (arts. 133.3 RC y 149.2 RS), la conformidad del Gobierno para las que propongan minoración de ingresos (133.4 RC) (preceptos de los que ya nos hemos ocupado en otro lugar) y la tramitación de las enmiendas que impugnan una sección completa como propuestas de veto (art. 149.1 RS).

82. Así, se han remitido y debatido con el proyecto de Ley de Presupuestos proyectos de Ley General Presupuestaria, concierto económico, cesiones de tributos, etc.

83. En particular, en el debate en el Congreso de los Presupuestos de vuelta del Senado, en el que aquél se pronuncia sobre las enmiendas introducidas por la Cámara Alta.

84. Véase S. Montpjo Vhlilla, "Aspectos del debate parlamentario de los Presupuestos para 1994", en Hacienda Pública Española, n. ${ }^{\circ}$ 85, 1983, pág. 133.

85. Ya desde el proyecto de Ley de Presupuestos para 1985, véase Diario de Sesiones del Congreso de los Diputados, Pleno, n. ${ }^{\circ} 174$, de 5 de diciembre 1984 , págs. 8058-8059. 
o en la anterior, iniciándose normalmente en lunes, con alguna excepción, y dedicada a las mismas cuestiones señaladas para el Congreso. En realidad son las citadas fiestas las que determinan la totalidad del calendario de tramitación, que se fija hacia atrás, a partir de ellas, en función de su variable situación en la semana. De lo que se trata es de que el debate en el Senado finalice con anterioridad a esas fechas, para que en la última semana de diciembre pueda celebrarse un Pleno del Congreso. No obstante, en los últimos años se ha iniciado la tendencia a adelantar una semana toda la tramitación, de forma que el Congreso pueda reunirse en los dias inmediatamente anteriores a Navidad.

d) Finalmente, comó decimos, el Pleno del Congreso se reúne, en la tercera o última semana del mes de diciembre, para pronunciarse sobre las enmiendas (sobre un veto, si llega a haberlo alguna vez) del Senado. Se trata también de un Pleno específico, al que sólo se incorporan otros textos legislativos pendientes de este último trámite o las convalidaciones de Reales Decretos-leyes pendientes.

- Por último, y aunque exceda ya del objeto de este trabajo, también en la publicación en el Boletín Oficial del Estado será prioritaria la Ley de Presupuestos sobre cualquier otra, aun aprobada con anterioridad: de lo que se trata es de que dicha publicación se produzca el 31 de diciembre, como muy tarde, de forma que pueda entrar en vigor el 1 de enero siguiente, sin que entre en juego la prórroga forzosa de los presupuestos anteriores prevista en el artículo 134.4 de la Constitución.

\section{FACULTADES DEL GOBIERNO SOBRE OTRAS INICIATIVAS}

Las facultades del Gobierno en el procedimiento legislativo no se limitan a sus propias iniciativas, que puede impulsar en la forma prevista en el apartado anterior, o retirar. Posee, además, medios de actuación sobre las iniciativas procedentes de otros sujetos, que le permiten asegurar la prioridad debida de los proyectos de ley, de una parte, y, de otra, que la totalidad de la legislación sea coherente, manteniéndose dentro de la orientación política fijada por el Gobierno en función de la competencia atribuida por el artículo 97 de la Constitución. Las facultades del Gobierno que le permiten mediar en la suerte parlamentaria de las proposiciones (manifestación de criterio, oposición a las financieras, participación en la inclusión en el orden del día, urgencia) llevan a concluir con Spagna Musso ${ }^{86}$

86. E. SPAGNA Musso, "L'iniziativa nella formazione delle leggi italiane", Il potere di iniziativa legislativa, vol. I, Napoles, 1958, págs. 201-202. Para R. PUNsET, la integración y subsidaridad resultan factibles gracias al trámite de la toma en consideración en el Congreso de los Diputados ("La iniciativa legislativa en el ordenamiento español, cit., págs. 76-77). En contra de entender el trámite de toma en consideración como explicación de la secundariedad de las iniciativas no gubernamentales, $M$. Herrero lera, "Comentario al artículo 87: iniciativa legislativa", cit., págs. 265-266): su secundariedad sólo puede ser fruto de la relación de confianza en la que descarga la acción de los gobiernos mayoritarios, pero, en ningún caso, el resultado de una supuesta subsidiariedad atribuida a la facultad de iniciativa cuando ésta se ejercita en forma de proposiciones de ley. 
que, no obstante, la pluralidad de sujetos a quienes la Constitución atribuye potestad de iniciativa legislativa, no se da entre aquéllos una relación de competencias, sino de integración, de forma que las iniciativas no gubernamentales operan secundariamente respecto de la que corresponde al Gobierno.

\subsection{Manifestación de su criterio respecto a las proposiciones de ley}

Los Reglamentos establecen, como primer requisito para iniciar la tramitación de las proposiciones de ley, es decir, para que puedan ser incluidas en el orden del día de una sesión plenaria, su remisión al Gobierno a un doble efecto: la manifestación de criterio respecto a la toma en consideración y la expresión de su conformidad a la tramitación si implicara aumento de los créditos o disminución de los ingresos presupuestarios. Son éstos dos supuestos distintos y de diferente fundamentación, que requieren su examen por separado.

En puridad, el Gobierno no tendría poder alguno sobre las proposiciones de ley, que constituyen el ejercicio de la iniciativa legislativa (o, más correctamente, de la propuesta de iniciativa), sobre la que deben decidir exclusivamente las Cámaras, titulares de aquélla (el Senado, respecto de las proposiciones originarias de sus miembros, el Congreso de los Diputados en los restantes casos), asumiéndola o no como propia mediante la toma en consideración.

Sin embargo, la cualidad que ostenta el Gobierno de co-titular de la iniciativa legislativa (pues hemos concluido que Gobierno y Parlamento son los únicos titulares, conforme al artículo 87.1 de la Constitución), junto con el carácter de su iniciativa como ordinaria y prevalente, puesta de manifiesto en el reconocimiento constitucional de la prioridad de los proyectos de ley, le sitúa en una posición especial sobre toda la función legislativa del Parlamento.

La función de dirección política está en el origen de la posición impulsora del Gobierno sobre el procedimiento legislativo. Sería también esta función la que permitiría al Gobierno "Supervisar" la actividad legislativa del Parlamento que no procede de él mismo, que le permite advertir sobre aquellas iniciativas que no se ajustan a la dirección por el fijadas y que, en consecuencia, deberían ser rechazadas por las Cámaras en el trámite de toma en consideración.

Evidentemente, la autonomía de las Cámaras no permite al Gobierno ir más allá: simplemente puede manifestar "su criterio respecto a la toma en consideración", conforme al artículo $126.2 \mathrm{RC}$, que carece de precepto paralelo en el Reglamento del Senado, lo que, inexplicablemente, y dado que las proposiciones recibidas de la otra Cámara son tramitadas por el Congreso como tales proposiciones de ley, excluido el trámite de toma en consideración (art. $125 \mathrm{RC}$ ), escaparían de la necesidad de expresión de criterio por el Gobierno ${ }^{87}$.

87. Ante el silencio del Reglamento del Senado, E. Angulo Rodríguz ("Comentario al artículo 88: iniciativa legislativa gubernamental", cit., pág. 252) plantea la duda de si la proposición remitida al Congreso queda sujeta a la obligación de remisión al Gobierno establecida por el artículo 126.2 y 3 , 
¿Cuál es la finalidad concreta perseguida por esa manifestación de criterio por el Gobierno, para la cual se le conceden nada menos que treinta días? Pues, en primer lugar, sería que la expresión de ese criterio pueda influir en la decisión de la Cámara sobre su tramitación, para lo cual se le da lectura, si lo hubiere, en el trámite de toma en consideración, antes de iniciar el debate. Se pretenderá con ello, caso de ser desfavorable, hacer reflexionar a la Cámara sobre las repercusiones negativas de la proposición, si es tramitada y concluye en ley, y sobre su contradicción con las finalidades y objetivos de la política del Gobierno, en general y para la materia concreta sobre la que verse aquella.

En sentido contrario, el Gobierno, de tener interés en la toma en consideración de la proposición, podría apoyarla entusiásticamente en el criterio manifestado, instando a la Cámara a su toma en consideración. Esto no será lo usual, puesto que el Gobierno puede hacer uso de su propia facultad de iniciativa mediante la presentación de proyectos de ley, que inician inmediatamente su tramitación y, por tanto, permiten una más rápida conclusión del procedimiento legislativo en aras a la regulación inmediata de una materia, pero cabría pensar en algún caso en que el Gobierno desee dejar la iniciativa al Grupo que le apoya, o a todos los Grupos parlamentarios, para resaltar el consenso logrado en la presentación de un texto.

No sería la única finalidad de este trámite la expresión de su criterio por el Gobierno. Éste puede ser inducido, mediante la presentación de la proposición, a reflexionar sobre la necesidad de regulación de la materia en cuestión, o sobre la existencia de un estado de opinión favorable a aquélla, que le lleven a presentar su propia visión plasmada en un proyecto de ley, para ser tramitado bien acumuladamente con la proposición, si la mayoría ( $y$, en consecuencia, normalmente también el Gobierno) apoya su toma en consideración, bien en solitario, desechada la propuesta contenida en la proposición al ser rechazada en el trámite de toma en consideración.

En todo caso, sea cual fuere su contenido favorable o negativo, se dará lectura al criterio del Gobierno antes de iniciarse el debate de toma en consideración sobre la proposición (art. 126.4 RC).

Lo cierto es que la práctica muestra que tan sólo en los primeros tiempos postconstitucionales llegó a hacerse uso de esta facultad del Gobierno, remitiendo al Congreso su criterio respecto de alguna proposición de ley. No ocurre así en el momento actual, ni en anteriores legislaturas. Se respeta, eso sí, el plazo de treinta días de que dispone el Gobierno para expresar su criterio (común, por otra parte, para con la expresión de su disconformidad con la tramitación de enmiendas).

ya que, en su literalidad, el artículo 125 no lo excluye. No creemos que esta sea la interpretación derivada del juego de los artículos 125 y 126 , que parecen disponer que la tramitación de las proposiciones del Senado se inicia en el Congreso a partir del trámite de toma en consideración. Siendo lá remisión al Gobierno para expresión de su criterio (que, por otra parte, tiene por objeto ser conocido en el citado trámite de toma en consideración) anterior a aquél, no sería de aplicación. Destaca también la incoherencia de la regulación Congreso-Senado R. PUNset, "La iniciativa legislativa en el ordenamiento español", cit., pág. 76 , nota 59. 
En ocasiones, el deseo de un Grupo parlamentario de incluir una proposición en el orden del día, expresado en la Junta de Portavoces, llevará al Gobierno a pronunciarse sobre la renuncia a dicho plazo. Si renuncia al transcurso del mismo, la inclusión de la proposición en el orden del día requerirá la unanimidad de la Junta para salvar el incumplimiento de un trámite reglamentario (art. 67.4 RC). La renuncia del Gobierno puede derivar de que no tiene inconveniente en su toma en consideración (proposiciones de la mayoría o de consenso) o, por el contrario, de que opta por su inmediato rechazo.

En cambio, la manifestación del mantenimiento del plazo reglamentario, cuando se le solicita su reducción, puede obedecer al deseo de retrasar lo más posible el debate sobre una proposición de ley de la oposición sobre asuntos controvertidos y de repercusión sobre la opinión pública (aborto), que, en definitiva se utilizan por aquélla como instrumentos de control del Gobierno. En algún caso, el no acceder a la reducción del plazo puede tener por objeto la fijación del criterio del Gobierno sobre la proposición (aunque luego éste no se manifieste por escrito como tal, sino mediante las instrucciones impartidas a la mayoría para que apoye o no la toma en consideración), y de hecho así lo ha expresado su representante alguna vez en la Junta de Portavoces, señalando que el Gobierno debía calcular las repercusiones económicas de la iniciativa.

\subsection{Oposición a una proposición o enmienda por delegación legislativa en vigor.}

El artículo 84 de la Constitución faculta al Gobierno para oponerse a la tramitación de una proposición de ley o una enmienda que fuere contraria a una delegación legislativa en vigor. Este precepto, recogido sólo en el Reglamento del Senado (art. 128), persigue que la Cámara no pueda ir contra sus propios actos: si ha otorgado por ley una delegación legislativa en el Gobierno, no puede luego actuar contra esa delegación, regulando directamente esa materia. El principio del contrarius actus requiere que, previamente, una ley derogue total o parcialmente la ley de delegación, como reconoce el propio artículo 84, que permite la presentación de una proposición de ley en este sentido.

El artículo 128 del Reglamento del Senado, sin paralelo en el del Congreso de los Diputados, establece un plazo de diez días desde la publicación de la proposición o enmienda para que el Gobierno aduzca su carácter contrario a una delegación legislativa en vigor, por escrito y motivadamente. Este escrito se publica y se incluye en el orden del día de la siguiente sesión plenaria. La tramitación de la "propuesta del Gobierno", como la llama el Reglamento, se realizará conforme a lo prevenido para los conflictos entre órganos constitucionales del Estado, es decir, parece entenderse que pueden presentarse propuestas por un Grupo parlamentario o veinticinco Senadores para que el Pleno se oponga a la propuesta del Gobierno, asimismo en escrito debidamente motivado, puesto que esta es la única previsión 
contenida en el artículo 186 RS para los conflictos de atribuciones con otros órganos constitucionales del Estado, decidiendo el Pleno.

Decisión que, obviamente, de ser negativa a la propuesta del Gobierno, podría dar lugar al planteamiento por éste de un conflicto de competencias ante el Tribunal Constitucional.

\subsection{Agilización procesal de las proposiciones de ley}

Cabría pensar que el Gobierno dispone, para agilizar la tramitación de las proposiciones cuya aprobación final le interese, prácticamente de los mismos medios que respecto de los proyectos de ley.

En efecto, recordemos que la facultad de inclusión prioritaria en el orden del día se refiere a un asunto (arts. 67.3 RC y 71.2 RS). No será fácil que el Gobierno haga uso de esta facultad a favor de una proposición, por lo que a la toma en consideración se refiere, puesto que éstas tienen su propia dinámica de cupos entre grupos. Pero una vez tomada en consideración e iniciada su tramitación, puede decirse que no hay diferencia procedimental alguna entre proyectos y proposiciones y, de alguna manera, se olvida su origen. Todo depende, pues, de la voluntad política que exista para su aprobación final, de la que también puede participar el Gobierno.

Sin embargo, tampoco parece lógico pensar que el Gobierno declare o solicite la declaración de urgencia de una proposición de ley. Para su agilización existe la vía de declaración por la Mesa, a instancia de dos Grupos parlamentarios o de una quinta parte de los diputados ${ }^{88}$ (art. 93.1 RC), de un Grupo parlamentario o veinticinco senadores (art. 133 RS). No es imposible, no obstante, que el Gobierno tenga interés en una proposición, y no parece que haya obstáculo a la tramitación de la solicitud en el Congreso (cuyo Reglamento se refiere a la tramitación por procedimiento de urgencia de un asunto y admite que el Gobierno la inste). Algo mayor es la dificultad en el Senado, cuyo Reglamento se refiere a los proyectos declarados urgentes por el Gobierno o el Congreso de los Diputados ${ }^{89}$, siguiendo el tenor del artículo 90.2 de la Constitución. Es coherente la referencia que este precepto contiene a los proyectos, serán los Reglamentos los que podrán en su caso dar cabida a una solicitud del Gobierno de tramitación por urgencia de las proposiciones, cuya declaración, creemos, debe quedar siempre en este supuesto en manos de las Cámaras.

Finalmente, la facultad de instar la celebración de sesión extraordinaria concedida al Gobierno por el artículo 73.2 de la Constitución, no está limitada en cuanto a su contenido, especificándose solamente que la convocatoria debe hacerse

88. A los que la Mesa pide también que justifiquen la solicitud antes de adoptar la decisión.

89. No así para la decisión de aplicación del procedimiento de urgencia por la Mesa, cuyo objeto no se especifica en el artículo $133.2 \mathrm{RS}$. 
sobre un orden del día determinado, en el que, por tanto, pueden tener cabida proposiciones de ley.

\subsection{La acumulación de proyectos y proposiciones}

La mejor arma que tiene el Gobierno contra una proposición de ley tomada en consideración en cierto sentido contra su voluntad, es la presentación de un proyecto de ley para que se tramite acumuladamente con aquélla. La toma en consideración puede haberse producido por la derrota de la mayoría -típica si ésta no es absoluta y cuenta con el apoyo de otros partidos para sostener al Gobierno, que pueden en una determinada cuestión votar contra él-, pero también posible en casos de mayoría absoluta ajustada, por la ausencia de diputados o el voto en conciencia de éstos, o simplemente por el voto contrario a las instrucciones de su Grupo. También puede ocurrir que la mayoría (y el Gobierno situado en su trasfondo) se hayan visto forzados a votar la iniciativa de un Grupo minoritario que le apoya, o incluso de un Grupo de la oposición, por razones de repercusión en la opinión pública, sin que aquélla le satisfaga ${ }^{9 \%}$.

En supuestos como los descritos, el Gobierno tendrá siempre en su mano la presentación de un proyecto de ley que recoja su perspectiva de la regulación de la materia. Por los medios que hemos señalado al hablar del orden del día, obtendrá la paralización de la tramitación de la proposición tomada en consideración, que "esperarâ" al transcurso del plazo de enmiendas del proyecto y su eventual debate de totalidad, al objeto de que la Comisión los tramite conjunta, y, previo un acuerdo de la Mesa, acumuladamente, con lo que la labor de la ponencia irá dirigida a la obtención del consenso de los grupos en torno a un texto, que en último caso podrá imponerse por mayoría.

Ya hemos señalado que, de facto, no se aplica en el aspecto temporal la prioridad debida de los proyectos de ley, en el sentido de que adelanten en su tramitación a las proposiciones presentadas sobre la misma materia ${ }^{91}$. No es

90. Una situación de este tipo se ha producido recientemente en relación con la proposición de Ley del Grupo parlamentario de Coalición Canaria, de regulación en materia de parejas de hecho, aunque en este caso no ha sido un proyecto de ley el presentado para desactivarla, sino una proposición de ley del Grupo parlamentario Popular [Proposición de Ley de Coalición Canaria, sobre reconocimiento de efectos jurídicos a las parejas de hecho estables y de modificación de determinados aspectos del Código Civil, Estatuto de los Trabajadores, Ley General de la Seguridad Social, Medidas para la Reforma de la Función Pública, Clases Pasivas del Estado y de la Ley del Impuesto sobre Sucesiones y Donaciones, tomada en consideración el 27 de mayo de 1997 (BOCG Congreso de los Diputados; Serie B, n. ${ }^{\circ}$ 90-2, de 3 de junio de 1997). Proposición de Ley orgánica de contrato de unión civil, presentada por el Grupo parlamentario Popular, tomada en consideración el 25 de noviembre de 1997 (BOCG Congreso de los Diputados, Serie B, n. ${ }^{\circ} 117-2$, de 5 de diciembre)].

91. Considera erróneamente que sí hay tramitación temporalmente prioritaria de los proyectos A. Rutz-Huirta CaRBonell (La iniciativa legislativa no gubernamental en España: configuración parlamentaria de las proposiciones de ley 1977-1996, Congreso de los Diputados, serie IV, Monografías n. 40, Madrid, 1998, pág. 80), sobre la base probablemente de las consideraciones ya aludidas de J. A Santamaría Pastor ("Comentario al artículo 89", cit., págs. 1278-1280) y J. F. Mrino Merchán ("Rasgos definidores de la iniciativa legislativa prevista en el artículo 87 de la Constitución", cit., págs. 55-56), 
tampoco una regla absoluta. Serán las conveniencias políticas del momento, si prima el rodillo o el consenso, las que harán inclinarse por una tramitación apresurada del proyecto o por una concitación del acuerdo en torno al mismo. En el primer caso, no parece que se respete la prohibición constitucional de que se impida el ejercicio de la iniciativa legislativa en los términos regulados por el artículo 87.

La práctica de la acumulación de iniciativas no tiene otro apoyo reglamentario que el referido a la acumulación por la Presidencia de debates para Pleno $\left(118.2 .1 .^{\circ} \mathrm{RC}\right)$ o de propuestas de veto (121.2 RS). Han sido, pues, acuerdos de la Mesa los que han iniciado esta tendencia, bien remitiendo el texto a la Comisión para su debate acumulado con otra iniciativa, bien respondiendo a la consulta de las respectivas Ponencias disponiendo la "tramitación agrupada" de varias iniciativas en un solo informe emanado de aquéllas.

\subsection{Proposiciones y enmiendas que supongan aumento de créditos o disminución del gasto}

Dice $\mathrm{Aja}^{92}$ que las proposiciones de ley tienen que superar dos grandes obstáculos para convertirse en ley: la toma en consideración y la barrera presupuestaria del artículo 134.6 de la Constitución. Tanto una como otra cumplirán una misma función de guillotina que hace abortar la iniciativa parlamentaria, una por obra de la mayoría parlamentaria que vota en contra, la otra por el Gobierno.

El fundamento de este precepto constitucional está relacionado con la autorización de gastos anuales que la Cámara concede al Gobierno mediante la aprobación de la Ley de Presupuestos. Se trata de que, durante el ejercicio presupuestario, no se desnaturalice por la Cámara esa autorización inicial sin el consentimiento del Gobierno, que dirige la política general de la que los Presupuestos son el instrumento económico-financiero. Por eso está en su mano el inicio de la tramitación parlamentaria del incremento de los gastos o ingresos previstos en aquellos, bien mediante la presentación de proyectos de ley (134.5 CE), bien dando su conformidad a las proposiciones o enmiendas que los supongan (134.6 CE). Como dice Biglino Campos ${ }^{93}$, cuando el Gobierno manifiesta su conformidad o disconformidad con la tramitación de la iniciativa, se limita a actuar conforme al encargo que le ha atribuido el propio Parlamento, garantizando la coherencia en la actuación de dicho órgano, mediante la facultad de paralizar las iniciativas.

quienes elaboran unas reglas puramente especulativas, ante la ausencia de normas reglamentarias, mediante las que podría resolverse la coincidencia de proyectos y proposiciones de ley. Hemos preferido ceñirnos a la realidad y no entrar en el terreno de lo ideal, en un punto de tan poco probable regulación reglamentaria por la pluralidad de situaciones posibles y tan sujeto a los acuerdos y los juegos de mayorías, como reconoce el propio Santamaría Pastor.

92. E. AJA, "Caracteres y principios generales del procedimiento legislativo", cit., págs. 163-164.

93. P. BıGlino CAMPOS, "Iniciativa legislativa", Enciclopedia jurídica básica, vol. III, Civitas, Madrid, 1995, pág. 3598. 
De las proposiciones y enmiendas que supongan aumento de créditos o disminución de ingresos ${ }^{94}$, desde el punto de vista de las facultades del Gobierno sobre iniciativas ajenas, nos interesa sólo destacar dos cuestiones: el momento en que la conformidad ha de producirse y la competencia para la decisión en caso de disparidad de criterio entre Gobierno y Parlamento.

Como hemos visto, las proposiciones de ley recibidas en el Congreso se remiten al Gobierno tan pronto son calificadas (126 RC), disponiendo aquél de un plazo de treinta días para manifestar, además de su criterio, su conformidad o no con la tramitación si implicara aumento de créditos o disminución de ingresos. No se prevén otrás consecuencias que la posibilidad de incluir la proposición en el orden del día del Pleno para su toma en consideración, transcurridos treinta días sin que el Gobierno hubiera negado expresamente su conformidad a la tramitación.

El Reglamento del Senado (art. 151.3) concede un plazo de diez días desde la remisión de la proposición al Gobierno para que éste manifieste su conformidad o disconformidad, que deberá ser motivada, entendiéndose el silencio asimismo como favorable a la tramitación. En este Reglamento sí se prevé la existencia de controversias sobre la calificación de las proposiciones de ley en el sentido que estudiamos, cuya resolución, como la de los incidentes que pudieran surgir en relación con la cuestión, se atribuye al Presidente del Senado. Esta es una solución correcta, en cuanto que mantiene en el ámbito parlamentario los medios para oponerse a una actuación del Gobierno que exceda del ámbito que la Constitución le confiere. En este sentido, Aja, también partidario de la atribución de la decisión a un órgano parlamentario ${ }^{95}$, aboga por la introducción de un elemento formal que determine el aumento de gastos (como la necesidad de aprobación de un suplemento de crédito), considerando básicos estos puntos para lograr que la iniciativa económica del Gobierno no implique asfixia de las iniciativas legislativas de los Grupos parlamentarios ${ }^{96}$. Esta segunda restricción formal

94. En cuanto a los sistemas existentes en el Derecho Comparado, pueden resumirse con J. M. SFrRano Alberca, ("La iniciativa legislativa en materia financiera: conflictos entre el Gobierno y el Parlamento", en Presupuesto y Gasto Püblico, n. ${ }^{\circ} 15,1983$, pág. 118) en la forma siguiente: el francés prohibe toda iniciativa parlamentaria en materia financiera que implique aumento de gasto o disminución de ingresos, el italiano solo obliga a indicar los medios para cubrir los nuevos gastos, mientras que el sistema español y el alemán adoptan una postura intermedia, exigiendo la conformidad del Gobierno para la tramitación de las iniciativas parlamentarias que impliquen aumento de gasto o disminución de ingresos. Véase también el Derecho Comparado sobre el consentimiento gubernamental en P. PÉrEz JimÉNEZ, "Las limitaciones a la iniciativa legislativa financiera en la Constitución Española", en Revista Española de Derecho Constitucional, n. ${ }^{\circ} 28,1990$, págs. 150-151.

95. En contra, P. PÉrrz Jiménez ("Las limitaciones a la iniciativa legislativa financiera en la Constitución Española", cit., pág. 152) quienes deben decidir si una enmienda o proposición reúne los requisitos para el ejercicio de la facultad es el órgano a favor del cual la facultad está establecida. En favor de la posición mantenida en el texto, J. M. Serrano Alberca, ("La iniciativa legislativa en materia financiera: conflictos entre el Gobierno y el Parlamentom, cit., pág. 119) y F. SanTaolalia López (Derecho parlamentario español, 1." ed., cit., pág. 222): "no puede aceptarse que el criterio del Gobierno sea vinculante si surge una discrepancia con los autores de las proposiciones de ley o enmiendas, pues ello equivaldría a hacerle juez y parte en la misma controversian.

96. E. AJA, "Caracteres y principios generales del procedimiento legislativo", cit., pág. 164. 
nos parece excesiva, en cuanto que, obviamente, existen otras proposiciones que materialmente inciden sobre los ingresos y gastos ${ }^{97}$.

En cuanto a las enmiendas; que pueden afectar tanto a proyectos como a proposiciones de ley ${ }^{98}$, comparten regulación con las proposiciones de ley en el Reglamento del Senado, variando simplemente los plazos de que dispone el Gobierno para oponerse a la tramitación (cinco días, en el procedimiento ordinario, dos días en el de urgencia). En el Congreso, según el Reglamento (art. 111), es la Ponencia encargada de redactar (151.3 RS) el informe sobre el proyecto la que remite al Gobierno, por conducto del Presidente del Congreso, las enmiendas que a su juicio pueden suponer aumento de créditos o disminución de ingresos presupuestarios, debiendo responder el Gobierno en quince días, transcurridos los cuales se entiende que el silencio expresa conformidad. Es importante señalar que el Gobierno puede manifestar en cualquier momento de la tramitación su disconformidad con las enmiendas que no le hayan sido consultadas en la forma señalada. Esta previsión deriva de que, a diferencia de las proposiciones, el Reglamento del Congreso no prevé el envío al Gobierno de todas las enmiendas como ocurre por contra en el Reglamento del Senado. Como de hecho sí se le remiten todas las enmiendas al concluir el plazo para su presentación, carece de sentido la utilización de la facultad del Gobierno en un momento posterior.

En cuanto al acto del Gobierno de disconformidad con la tramitación, no aparece regulado, como ocurre con algunas otras de sus competencias constitucionales, en la Ley del Gobierno. La Constitución no exige decisión del Consejo de Ministros. Pérez Jiménez ${ }^{99}$ llega a la conclusión de que la naturaleza y circunstancias en que debe operar la institución (por ejemplo, respecto de enmiendas transaccionales presentadas en el curso de un debate) impiden exigir un acuerdo expreso del órgano colegiado, presumiéndose que si uno de los miembros utiliza la facultad se presume que actúa en nombre del Gobierno.

Los efectos de la disconformidad del Gobierno consisten en la paralización de la iniciativa, sea proposición o enmienda, que no puede ser tramitada. En el primer caso, no se producirá el debate de toma en consideración y, en el segundo, no cabe el pronunciamiento de la Comisión sobre la aceptación o rechazo de la enmienda. No deberá, en consecuencia, ser tampoco examinada por la Ponencia.

Los conflictos que puedan plantearse derivarían de la tramitación por las Cámaras de una iniciativa a la que el Gobierno ha negado su conformidad, en cuyo caso podrá éste interponer un recurso de inconstitucionalidad por inobservancia del artículo 134.6 de la Constitución, en la que el Tribunal deberá dilucidar

97. Véase sobre esta cuestión, P. PÉRez JiménfZ, "Las limitaciones a la iniciativa legislativa financiera en la Constitución Españolan, cit., págs. 142-150.

98. Como señala acertadamente el artículo $151.3 \mathrm{RS}$, frente al $111 \mathrm{RC}$, que se refiere sólo a enmiendas a proyectos. El precepto del Reglamento del Senado presenta el defecto, en cambio, de encontrarse enclavado en el procedimiento presupuestario al que no pertenece stricto sensu, aunque sí son especialidades derivadas de la incidencia de las iniciativas sobre los Presupuestos aprobados.

99. P. PÉRfz JimÉNEz, "Las limitaciones a la iniciativa legislativa financiera en lá Constitución Españolan, cit., pág. 152. 
si el contenido material de la iniciativa incidía en el ámbito fijado por el precepto constitucional. Incluso antes de la aprobación de la ley, el Gobierno podrá plantear un conflicto de atribuciones contra el acuerdo que permita proseguir la tramitación, alegando que tiene atribuida constitucionalmente la competencia para negar la conformidad ${ }^{100}$.

Las Cámaras no necesitan plantear conflicto alguno ${ }^{101}$ : basta la decisión del Presidente del Senado, conforme a su Reglamento, o, en el Congreso, con hacer caso omiso de la disconformidad del Gobierno si existe discrepancia en la calificación de repercusión presupuestaria de la iniciativa, para proseguir la tramitación ${ }^{102}$.

Por último, en lo que se refiere a la práctica parlamentaria, siendo relativamente frecuente la disconformidad del Gobierno en los primeros tiempos postconstitucionales (en siete ocasiones en la I Legislatura y dieciséis en la II), posteriormente llega casi a desaparecer, por no compensar la erosión política que origina su manifestación, en particular respecto de las enmiendas, siendo preferible actuar por la vía del rechazo en votación por la mayoría.

100. En este sentido, J. M. Serrano AlbFrCA, "La iniciativa legislativa en materia financiera: conflictos entre el Gobierno y el Parlamento", cit., pág. 119. R. Punsfe, "La fase central del procedimiento legislativo", cit., pág. 114.

101. Pero los enmendantes arbitrariamente defraudados por la calificación, como señala R. PuNSET, ibidem, pág. 115, pueden interponer un recurso de amparo (exartículo 42 LOTC), aunque sin efectos suspensivos, y por tanto ineficaz, dado que la tardanza en resolver del Tribunal Constitucional superará con creces el período de tramitación de la ley.

102. Como recuerda F. Santaolalla López, Derecbo parlamentario español, cit., pág. 262, nota 9, en los debates del Reglamento vigente, el señor Solé Tura defendió que la Comisión de Presupuestos o el Pleno resolviesen las discrepancias, manifestando el representante de UCD que ello supondría usurpar la facultad constitucional que tiene el Gobierno, pero que en última instancia sería la Mesa de Congreso quien decidiese si el Gobierno ejercía su facultad dentro de sus límites constitucionales y reglamentarios (Diario de Sesiones del Congreso de los Diputados, Comisión de Reglamento, $\mathrm{n} .{ }^{\circ} 29$, págs. 1374 y ss y n. ${ }^{\circ}$ 30, págs. 1407 y ss). 